\title{
The Interplay between the Digital Services Act and Sector Regulation: How Special is Copyright?
}

\author{
João Pedro Quintais ${ }^{\dagger}$ and Sebastian Felix Schwemer ${ }^{\ddagger}$
}

\begin{abstract}
On 15 December 2020, the European Commission published its proposal for the Digital Services Act, which is expected to be adopted before summer 2022. It carries out a regulatory overhaul of the 21-yearold horizontal rules on intermediary liability in the e-Commerce Directive and introduces new due diligence obligations for intermediary services.

Our analysis illuminates an important point that has so far received little attention: how would the Digital Services Act's rules interact with existing sector-specific lex specialis rules? In this paper, we look specifically at the intersection of the Digital Services Act with the regime for online content sharing service providers (OCSSPs) set forth in art. 17 of Directive (EU) 2019/790 on copyright in the Digital Single Market (CDSM Directive). At first glance, these regimes do not appear to overlap as the rules on copyright are lex specialis to the Digital Services Act. A closer look shows a more complex and nuanced picture. Our analysis concludes that the DSA will apply to OCSSPs insofar as it contains rules that regulate matters not covered by art. 17 CDSM Directive, as well as specific rules on matters where art 17 leaves margin of discretion to Member States. This includes, to varying degrees, rules in the DSA relating to the liability of intermediary providers and to due diligence obligations for online platforms of different sizes. Importantly, we consider that such rules apply even where art. 17 CDSM Directive contains specific (but less precise) regulation on the matter.

From a normative perspective, this might be a desirable outcome, to the extent that the DSA aims to establish "uniform rules for a safe, predictable and trusted online environment, where fundamental rights enshrined in the Charter are effectively protected". Based on our analysis, we suggest a number of clarifications that might be help achieve that goal.
\end{abstract}

\footnotetext{
* Acknowledgement: This research is part of the reCreating Europe project, which has received funding from the European Union's Horizon 2020 research and innovation programme under grant agreement No 870626. João Pedro Quintais's research in this article is also funded by the VENI Project "Responsible Algorithms: How to Safeguard Freedom of Expression Online" funded by the Dutch Research Council (grant number: VI.Veni.201R.036). The authors wish to thank Alexander Peukert, Felix Reda, Christoph Schmon, Nuno Sousa e Silva, Jens Schovsbo for their valuable comments. All errors remain ours.

† Assistant Professor, Institute for Information Law (IViR), University of Amsterdam. E-mail: j.p.quintais@uva.nl.

¥ Associate Professor, Centre for Information and Innovation Law (CIIR), University of Copenhagen, and Adjunct Associate Professor, Norwegian Research Center for Computers and Law (NRCCL), University of Oslo. E-mail: sebastian.felix.schwemer@jur.ku.dk
} 


\section{Introduction}

Online platforms provide the main point of access to information and other content in the digital age, whether through "search engines, social networks, micro-blogging sites or video-sharing platforms". Although these platforms bring economic and social benefits, they also enable the unprecedented spread of illegal content, including incitement to terrorism, hate speech, and copyright infringement..$^{5}$ This is particularly true for so-called Big Tech platforms - like Facebook and YouTube - that have amassed significant power over online speech and commerce in the past decade. ${ }^{6}$

Against this background, the EU and its Member States have proposed and adopted a growing number of laws and policies to regulate online content, with a focus on enhancing the responsibility of hosting platforms for user-uploaded illegal content. ${ }^{7}$ The centerpiece of the European Commission's strategy in this respect was published on 15 December 2020: the proposal for a Regulation on a Single Market for Digital Services (Digital Services Act, DSA) ${ }^{8}$, which amends the e-Commerce Directive ${ }^{9}$ for certain internet intermediaries. The DSA carries out a regulatory overhaul of the 21-year-old horizontal rules on intermediary liability in the Directive.

In this article, we use doctrinal legal analysis to look at how the DSA's rules interplay with sectorspecific, lex specialis rules. This question is relevant both for specific EU legislation, such as on

\footnotetext{
4 Commission, 'Tackling Illegal Content Online Towards an enhanced responsibility of online platforms', $\mathrm{COM} / 2017 / 0555,2$.

${ }^{5}$ Recommendation of 1.3.2018 on measures to effectively tackle illegal content online, C/2018/1177.

${ }^{6}$ Nicolas Suzor, Lawless: The Secret Rules That Govern Our Digital Lives (Cambridge University Press 2019).

${ }^{7}$ Mathias Vermeulen, 'Online Content: To Regulate or Not to Regulate - Is That the Question? | Association for Progressive Communications' (Association for Progressive Communications 2019) Issue Paper $<$ https://www.apc.org/en/pubs/online-content-regulate-or-not-regulate-question $>$ accessed 25 November 2020. Commission, 'Tackling Illegal Content Online Towards an enhanced responsibility of online platforms', COM/2017/0555; Commission, 'Recommendation of 1.3.2018 on measures to effectively tackle illegal content online', C/2018/1177.

${ }^{8}$ Proposal for a Regulation of the European Parliament and of the Council on a Single Market for Digital Services (Digital Services Act) and amending Directive 2000/31/EC $\mathrm{COM} / 2020 / 825$ final. For ease of reference, we refer to this legislative proposal as "DSA" in the main body of the text and "DSA proposal" in the footnotes. Unless otherwise specified, our analysis refers to the text of the original proposals and not to the amendments advanced so far in the legislative process. For further details on this process, see European Parliament, Legislative Train Schedule, DSA proposal, https://www.europarl.europa.eu/legislative-train/theme-a-europe-fit-for-the-digital-age/file-digital-services-act.

${ }^{9}$ Directive 2000/31/EC of the European Parliament and of the Council of 8 June 2000 on Certain Legal Aspects of Information Society Services, in Particular Electronic Commerce, in the Internal Market [2000] OJ L178/1 (e-Commerce Directive).
} 
copyright $^{10}$ and terrorist content ${ }^{11}$, as well as national sector regulation. The focus of our legal analysis, however, is on online platforms and copyright-protected material. ${ }^{12}$

With regard to copyright-protected material, art. 17 of the Directive on copyright in the Digital Single Market (CDSM Directive), which preceded the DSA, establishes a new liability regime for online content-sharing service providers (OCSSPs). These rules had to be implemented by EU Member States on 7 June 2021. ${ }^{13}$ Both art. 17 CDSM Directive as well as multiple provisions of the DSA impose obligations on how online platforms deal with illegal information. Whereas art. 17 CDSM Directive targets copyright infringing content, the DSA proposal targets illegal content in general, including that which infringes copyright.

This raises the question of how the two frameworks will interact once both enter into force. Besides the different nature of the legal instruments (Regulation vs Directive), this question is of high relevance, first and foremost where the frameworks differ. At first sight, these regimes may not appear to overlap since art. 17 CDSM Directive is lex specialis to the DSA. A closer look, however, reveals a much more complex picture. The proposed DSA regulation is complementary to art. 17 CDSM Directive, and imposes a number of additional obligations on online platforms that qualify as OCSSPs. But the extent to which these obligations apply-and in some case whether they do apply-is unclear. This article examines and maps this underexplored intersection between the CDSM Directive and the DSA. ${ }^{14}$ Our legal analysis illuminates a point that has so far received little attention: the extent to which the DSA provides a new regulatory approach to online platforms through horizontal rules that extend to most corners of EU law, even where that reach appeared precluded or limited by specific legislation to be implemented at national level. In the case of copyright, the issue is especially complex due to its territorial nature, leading to a multi-

\footnotetext{
${ }^{10}$ Directive (EU) 2019/790 of the European Parliament and of the Council of 17 April 2019 on copyright and related rights in the Digital Single Market (CDSM Directive).

${ }^{11}$ See European Parliament, Press Room, New rules adopted for quick and smooth removal of terrorist content online (28.04.2021), https://www.europarl.europa.eu/news/en/press-room/20210422IPR02621/new-rules-adopted-for-quickand-smooth-removal-of-terrorist-content-online (noting the approval in the European Parliament of the post-trilogue version of the new Regulation).

${ }^{12}$ For the purposes of simplicity, we use the term copyright-protected "material" to cover both works protected by copyright and other subject matter protected by related rights.

${ }^{13}$ Most Member States failed to implement the directive at the deadline, leading the European Commission to start infringement proceedings. See European Commission, Press Release, "Copyright: Commission calls on Member States to comply with EU rules on copyright in the Digital Single Market" (26.07.2021), https://ec.europa.eu/commission/presscorner/detail/en/MEX_21_3902.

${ }^{14}$ In addition to our work, existing research on this topic includes e.g. Alexander Peukert and others, 'European Copyright Society: Comment on Copyright and the Digital Services Act Proposal' (European Copyright Society 2022) <https://europeancopyrightsocietydotorg.files.wordpress.com/2022/01/2022-01-17-ecs-comment-on-copyright-and-thedigital-services-act-proposal-3.pdf>; Eleonora Rosati, 'The Digital Services Act and Copyright Enforcement: The Case of Article 17 of the DSM Directive', Unravelling the Digital Services Act Package (European Audiovisual Observatory 2021).
} 
layered enforcement problem. ${ }^{15}$ Varying national implementations of art. 17 CDSM Directive, which are outside the scope of this paper, would further complicate matters.

This article carries out a doctrinal analysis of this particular legal question. To be sure, there are additional legal and empirical angles from which to address the underlying objective of the legal instruments under analysis. As noted, both the CDSM Directive (in a more targeted sector specific manner) and the DSA (in a general horizontal approach) aim to curb the increasing power and "digital dominance" of Big Tech companies, primarily by subjecting them to additional liability and obligations for the illegal (and even the harmful) content they host. ${ }^{16}$ Our analysis only captures a small part of the regulatory and normative complexity involved in this task.

On the one hand, part of the legal solutions to curb platform power are found elsewhere in proposals that attempt to address the anti-competitive practices of Big Tech as so-called "gatekeepers", such as the Digital Markets Act. ${ }^{17}$ On the other hand, much of the power enjoyed by these platforms results from content moderation rules, technologies and processes adopted by "platforms" proper, i.e., a form of private ordering. This type of regulation can fit into two broad categories. First, Terms of Service and similar documents (community guidelines, etc.) adopted by platforms, referred to by some authors as "platform law". ${ }^{18}$ In EU law, this would include for instance what is covered by the definition of "terms and conditions" in the proposed DSA. ${ }^{19}$ Second, regulation by platforms can be carried out through technological devices or code, such as in the case of algorithmic moderation systems (e.g., for filtering of illegal content). ${ }^{20}$ Big Tech platforms

\footnotetext{
${ }^{15}$ On the issue of copyright territoriality and the internet, see e.g. Thomas Dreier, 'Copyright in the Times of the Internet - Overcoming the Principle of Territoriality within the EU' (2017) 18 ERA Forum 7. For a broader perspective of the territoriality of EU law with reference inter alia to copyright, see Maciej Szpunar, 'Territoriality of Union Law in the Era of Globalisation', volution des rapports entre les ordres juridiques de l'Union européenne, international et nationaux. Liber Amicorum Jiř́ Malenovský (Éditions Bruylant 2020).

${ }^{16}$ Ilaria Buri and Joris van Hoboken, 'The DSA Proposal's Impact on Digital Dominance' (Verfassungsblog, 30 August 2021) < https://verfassungsblog.de/power-dsa-dma-01/> accessed 7 October 2021.

${ }^{17}$ Proposal for a REGULATION OF THE EUROPEAN PARLIAMENT AND OF THE COUNCIL on contestable and fair markets in the digital sector (Digital Markets Act) COM/2020/842 final.

18 David Kaye, Speech Police: The Global Struggle to Govern the Internet (Columbia Global Reports 2019). More broadly see, e.g., Belli L, \& Venturini J. Private ordering and the rise of terms of service as cyber-regulation. Internet Policy Review. Vol 5. N 4. (2016). https://policyreview.info/articles/analysis/private-ordering-and- rise-terms-servicecyber-regulation

${ }^{19}$ Art. 2(q) proposed DSA: 'terms and conditions' means all terms and conditions or specifications, irrespective of their name or form, which govern the contractual relationship between the provider of intermediary services and the recipients of the services. See also the more detailed definition of "terms and conditions" in art. 2(10) of Regulation (EU) 2019/1150 of the European Parliament and of the Council of 20 June 2019 on promoting fairness and transparency for business users of online intermediation services. For an analysis of art. 12 DSA proposal, see Naomy Appelman, João Pedro Quintais and Ronan Fahy, 'Article 12 DSA: Will Platforms Be Required to Apply EU Fundamental Rights in Content Moderation Decisions?' (DSA Observatory) < https://dsa-observatory.eu/2021/05/31/article-12-dsa-will-platforms-berequired-to-apply-eu-fundamental-rights-in-content-moderation-decisions/> accessed 28 August 2021; Naomy Appelman, João Pedro Quintais and Ronan Fahy, 'Using Terms and Conditions to apply Fundamental Rights to Content Moderation' (Verfassungsblog) < https://verfassungsblog.de/power-dsa-dma-06/> accessed 7 October 2021.

${ }^{20}$ Robert Gorwa, Reuben Binns and Christian Katzenbach, 'Algorithmic Content Moderation: Technical and Political Challenges in the Automation of Platform Governance' (2020) 7 Big Data \& Society $2053951719897945 .$.
} 


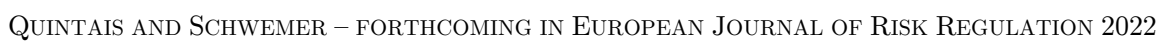

have long developed complex terms and conditions and content recognition systems or tools that de facto govern their treatment of illegal and harmful content they host. ${ }^{21}$ In the particular case of copyright-protected content, these systems are perhaps at their most developed, and include well known examples such as YouTube's suite of copyright management tools - most notably ContentID - and Facebook's Rights Manager. ${ }^{22}$ This is not surprising, since "[e]mpirically, copyright law accounts for most content removal from online platforms, by an order of magnitude". ${ }^{23}$ Outside the sphere of copyright, platforms mostly use different content recognition tools for separate types of illegal or harmful/undesirable content (e.g. terrorism, violence, "toxic speech", child abuse, sexual content, spam) that in simple terms "match content to known images, text or video in a database and classification tools which can classify new images as part of pre-defined categories" ${ }^{24}$ Although our analysis makes reference to some of these aspects, it focuses on the legal question above, and can therefore only offer a modest contribution to this debate.

The article proceeds as follows. After this introduction (0), we provide a snapshot of the complex regime set out in art. 17 CDSM Directive, providing a baseline understanding for the subsequent analysis (2). We then move to the heart of our analysis, explaining why and how the DSA liability regime and especially its asymmetric due diligence obligations apply to online platforms that host and provide access to copyright protected content, despite - and in addition to - the specific rules in art. 17 CDSM Directive, to be implemented into national law in light of Guidance issued by

\footnotetext{
${ }^{21}$ See for an overview DSA Impact Assessment - Part 2/2 (Brussels, 15.12.2020) SWD(2020) 348 Final, Annex 11, Content Recognition Tools, pp. 192ff.

22 See: YouTube, https://support.google.com/youtube/answer/9245819?hl=en\&ref topic=9282364; Facebook, https://rightsmanager.fb.com/. Popular third party tools include those provided by Audible Magic and Pex. See: Audible Magic, https://www.audiblemagic.com/; Pex, https://pex.com/. For an overview of content recognition systems for copyright at EU level, see Jean-Philippe Mochon and Sylvain Humbert, 'CSPLA Mission on the Tools for the Recognition of Content Protected by Online Sharing Platforms: State of the Art and Proposals' (CLSPA - Superior Council for Literary and Artistic Property (France) 2020)<https://www.culture.gouv.fr/en/Sites-thematiques/Propriete-litteraire-et-artistique/Conseil-superieur-de-la-propriete-litteraire-et-artistique/Travaux/Missions/Mission-duCSPLA-sur-les-outils-de-reconnaissance-des-contenus-proteges-par-les-plateformes-de-partage-en-ligne-etat-de-l-art-etpropositions >; EUIPO, 'Automated Content Recognition. Discussion Paper - Pase 1: Existing Technologies and Their Impact on IP' (EUIPO 2020) Discussion Paper < https://euipo.europa.eu/ohimportal/en/web/observatory/news/-/action/view/8365301>. For a critical analysis of the rethoric surrounding the adoption of these tools in the legislative process of the CDSM Directive, see Annemarie Bridy, 'The Price of Closing the "Value Gap": How the Music Industry Hacked EU Copyright Reform' (2020) 22 Vanderbilt Journal of Entertainment \& Technology Law, volume 22, pp. 323358 (2020) 323 .

${ }^{23}$ Peukert and others (n 11) 2. A good illustration is provided in YouTube's first ever transparency report. For instance, during the first half of 2021, there were over 730 million unique claims or copyright removal requests made through the platform's ContentID system. See YouTube, 'YouTube Copyright Transparency Report' (YouTube 2021) 5 $<$ https://blog.youtube/news-and-events/access-all-balanced-ecosystem-and-powerful-tools/> accessed 20 January 2022 .
}

${ }^{24}$ DSA Impact Assessment - Part 2/2 (Brussels, 15.12.2020) SWD(2020) 348 Final, Annex 11, Content Recognition Tools, pp. $192 \mathrm{ff}$. 


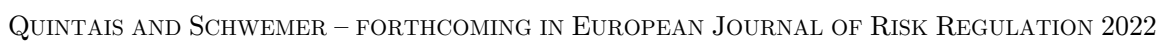

the Commission $^{25}$ (3). We conclude with key findings of our analysis and suggestions for clarifications in the further legislative process (4).

\section{OCSSPs and art. 17 CDSM Directive}

\subsection{Overview}

OCSSPs are a novel concept defined in art. 2(6) CDSM Directive, with further guidance in recitals 62 and 63 . They are providers of an information society service whose main purpose is to store and give the public access to a large amount of protected content by its users, provided it organises and promotes that content for profit-making purposes. The definition also contains a number of exclusions aimed at services that are either not aimed primarily at giving access to copyrightprotected content and/or are primarily not for-profit (e.g., service providers like Skype, Dropbox, eBay, Wikipedia, ArXiv.org and GitHub). ${ }^{26}$

While this concept is new to the copyright acquis, OCSSPs do not appear to constitute a wholly new category of service providers in a technological or business sense. Rather, this is a new legal category covering a type of provider of hosting services whose activities or functions were previously regulated in different legal instruments, such as the e-Commerce Directive ${ }^{27}$, the InfoSoc Directive $^{28}$ and the Enforcement Directive. ${ }^{29}$ Figure 1 below represents this relationship.

\footnotetext{
${ }^{25}$ Communication from the Commission to the European Parliament and the Council, Guidance on Article 17 of Directive 2019/790 on Copyright in the Digital Single Market, COM/2021/288 final (hereafter "Guidance Art. 17 CDSM Directive").

${ }^{26}$ See art. 2(6) para.2 CDSM Directive. See also art. 17(6) DSM Directive on startup OCCSPs.

${ }^{27}$ See art. 14 e-Commerce Directive.

${ }^{28}$ See especially art. 3 (right of communication to the public) and art. 8(3) (injunctions against intermediaries whose services are used by a third party to infringe a copyright or related right) InfoSoc Directive.

${ }^{29}$ See especially arts. 5 and 11 Directive 2004/48/EC of the European Parliament and of the Council of 29 April 2004 on the enforcement of intellectual property rights (OJ L 157, 30.4.2004) (Enforcement Directive).
} 


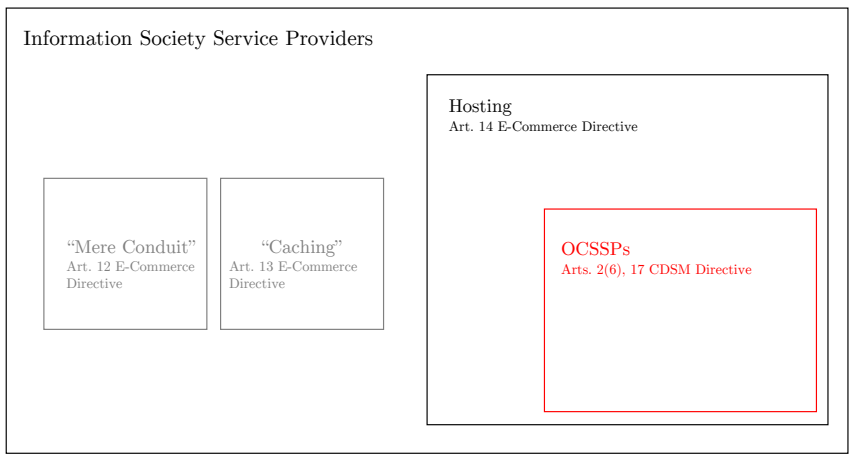

Figure 1. OCSSPS in the context of the e-Commerce Directive

Art. 17 is an extremely complex legal provision. As Dusollier notes, it is the "monster provision" of the Directive, "both by its size and hazardousness". ${ }^{30}$ There is perhaps no better testament to this than the wealth of legal scholarship that already exists on art. 17, even before its national implementation deadline. ${ }^{31}$

\footnotetext{
${ }^{30}$ Séverine Dusollier, 'The 2019 Directive on Copyright in the Digital Single Market: Some Progress, a Few Bad Choices, and an Overall Failed Ambition' (2020) 57 Common Market Law Review 979.

${ }^{31}$ There is already significant scholarship on art. 17 CDSM Directive. See e.g. Matthias Leistner, 'European Copyright Licensing and Infringement Liability Under Art. 17 DSM-Directive Compared to Secondary Liability of Content Platforms in the U.S. - Can We Make the New European System a Global Opportunity Instead of a Local Challenge?' [2020] Zeitschrift für Geistiges Eigentum/Intellectual Property Journal (ZGE/IPJ) <https://papers.ssrn.com/abstract $=3572040>$ accessed 17 April 2020; Axel Metzger and others, 'Selected Aspects of Implementing Article 17 of the Directive on Copyright in the Digital Single Market into National Law - Comment of the European Copyright Society' (European Copyright Society 2020) European Copyright Society Opinion ID $3589323<$ https://papers.ssrn.com/abstract $=3589323>$ accessed 4 July 2020; Sebastian Felix Schwemer, 'Article 17 at the Intersection of EU Copyright Law and Platform Regulation' (2020) 3/2020 Nordic Intellectual Property Law Review <https://papers.ssrn.com/abstract $=3627446>$ accessed 4 July 2020; Thomas Spoerri, 'On Upload-Filters and Other Competitive Advantages for Big Tech Companies under Article 17 of the Directive on Copyright in the Digital Single Market' (2019) 10 JIPITEC $<$ https://www.jipitec.eu/issues/jipitec-10-2-2019/4914>; Giancarlo Frosio, 'Reforming the C-DSM Reform: A UserBased Copyright Theory for Commonplace Creativity' [2020] IIC - International Review of Intellectual Property and Competition Law <https://doi.org/10.1007/s40319-020-00931-0> accessed 4 July 2020; Maxime Lambrecht, 'Free Speech by Design - Algorithmic Protection of Exceptions and Limitations in the Copyright DSM Directive' (2020) 11 JIPITEC < http://www.jipitec.eu/issues/jipitec-11-1-2020/5080>; Gerald Spindler, 'The Liability System of Art. 17 DSMD and National Implementation - Contravening Prohibition of General Monitoring Duties?' 10 JIPITEC 334; Krzysztof Garstka, 'Guiding the Blind Bloodhounds: How to Mitigate the Risks Art. 17 of Directive 2019/790 Poses to the Freedom of Expression', Intellectual Property and Human Rights (4th edn, KLuwer Law International 2019) $<$ https://papers.ssrn.com/abstract $=3471791>$ accessed 8 April 2020; Dusollier (n 27); Jan Bernd Nordemann and Julian Wiblinger, 'Art. 17 DSM-RL - Spannungsverhältnis Zum Bisherigen Recht?' [2020] GRUR 569; Martin Husovec and João Pedro Quintais, 'How to License Article 17? Exploring the Implementation Options for the New EU Rules on Content-Sharing Platforms under the Copyright in the Digital Single Market Directive' (2021) 70 GRUR International 325; Martin Husovec and João Quintais, 'Too Small to Matter? On the Copyright Directive's Bias in Favour of Big Right-Holders' in Tuomas Mylly and Jonathan Griffiths (eds), Global Intellectual Property Protection and New
} 
Quintais AND SCHWEMER - FORThCOMING IN EUROPEAN JouRNAL OF RiSk ReGUlation 2022

In simple terms, art. 17 states that OCSSPs carry out acts of communication to the public when they give access to works/subject matter uploaded by their users. As a result, these providers become directly liable for their users' uploads. They are also expressly excluded in paragraph (3) from the hosting safe harbour for copyright relevant acts, previously available to many of them under art. 14(1) e-Commerce Directive. Arguably, this makes art. 17 lex specialis to the e-Commerce Directive. ${ }^{32}$

The provision then introduces a complex set of rules to regulate OCSSPs, including a liability exemption mechanism in paragraph (4), and a number of what can be referred to as mitigations measures and safeguards.

The liability exemption mechanism is comprised of best efforts-obligations for preventive measures, including those aimed at filtering content ex ante, at notice and stay-down, and at notice and takedown. ${ }^{33}$ In particular, art. 17(4) establishes three cumulative conditions for this liability exemption mechanism. The first condition is that OCSSPs must demonstrate to have made best efforts to obtain an authorisation. ${ }^{34}$ If this obligation is met, then OCSSPs are subject to two further cumulative conditions in paragraphs (b) and (c). Namely, they must demonstrate that they have made: (i) best efforts to ensure the unavailability of specific works for which the right holders have provided them with the relevant and necessary information; and (ii) acted expeditiously, subsequent to notice from right holders, to take down infringing content and made best efforts to prevent its future upload. Condition (i) appears to impose what critics label an upload filtering obligation, whereas condition (ii) introduces both a notice-and-takedown mechanism (similar to that of art. 14 e-Commerce Directive) and a notice-and-stay-down (or re-upload filtering) obligation. ${ }^{35}$

Among the mitigations measures and safeguards that art. 17 includes we find the following. First, the requirements of a proportionality assessment and the identification of relevant factors for preventive measures. ${ }^{36}$ Second, a special regime for small and new OCSSPs. ${ }^{37}$ Third, a set of mandatory exceptions akin to user rights or freedoms that are designed as obligations of result

Constitutionalism. Hedging Exclusive Rights. (OUP 2021) < https://papers.ssrn.com/abstract=3835930> accessed 3 May 2021.

${ }^{32}$ See e.g. Miquel Peguera, 'The New Copyright Directive: Online Content-Sharing Service Providers Lose ECommerce Directive Immunity and Are Forced to Monitor Content Uploaded by Users (Article 17).' (Kluwer Copyright Blog, 26 September 2019) <http://copyrightblog.kluweriplaw.com/2019/09/26/the-new-copyright-directive-online-contentsharing-service-providers-lose-ecommerce-directive-immunity-and-are-forced-to-monitor-content-uploaded-by-users-article-17/> accessed 13 April 2020.

${ }^{33}$ Art. 17(4) (b) and (c) CDSM Directive.

${ }^{34}$ On the interpretation of this condition, see e.g. Metzger and others (n 28).

${ }^{35}$ For an analysis of these preventive obligations see Martin Husovec, "How Europe Wants to Redefine Global Online Copyright Enforcement" (2019). In: Tatiana Eleni Synodinou (ed.), Pluralism or Universalism in International Copyright Law (Kluwer law, Forthcoming), http://dx.doi.org/10.2139/ssrn.3372230.

${ }^{36}$ Art. 17 (5) CDSM Directive.

${ }^{37}$ Art. 17 (6) CDSM Directive. 
expressly based on fundamental rights. ${ }^{38}$ Fourth, a clarification that art. 17 does not entail general monitoring, however, without providing much insight on its relation to prohibition contained in art. 15 e-Commerce Directive. ${ }^{39}$ Fifth, a set of procedural safeguards, including an in-platform complaint and redress mechanism and rules on out of court redress mechanisms. ${ }^{40}$

Finally, art. 17(10) tasks the European Commission (EC) with organising stakeholder dialogues to ensure uniform application of the obligation of cooperation between OCSSPs and rights holders and to establish best practices regarding the appropriate industry standards of professional diligence. After much delay, the Guidance from the Commission was finally published as a Communication on 4 July 2021, a mere working day before the transposition deadline of the CDSM Directive on 7 June. The Guidance was adopted as a Communication, and is therefore not binding. ${ }^{41}$ Furthermore, as the Guidance itself states, it might have to reviewed in light of the CJEU judgement in C-401/192. ${ }^{42}$ In fact, the Opinion of the Advocate General (AG) in that case suggests that key aspects of the Guidance might not be in conformity with fundamental rights. ${ }^{43}$ Still, the Guidance is a rich document that is bound to influence national implementations. This Guidance, we note, only refers to the DSA once. ${ }^{44}$

To be sure, Big Tech platforms like YouTube (ContentID, Copyright Match Tool and Web Form $^{45}$ ) and Facebook (Rights Manager) already contain content recognition tools including the type of filtering and blocking measures required by art. 17's liability exemption mechanism. But that is not necessarily true for the majority of other smaller-scale platforms, who will be required to implement tools obtained from private third-party providers, like Audible Magic and Pex. ${ }^{46}$ In this sense, an unintended consequence of art. 17 is that it translates into a competitive advantage for bigger OCSSPs over smaller providers. ${ }^{47}$ Additionally, it is also clear that the most advanced of current filtering technologies - based on matching fingerprinting or hashing algorithms - are incapable of recognizing the types of uses covered by mandatory copyright exceptions or

\footnotetext{
${ }^{38}$ Art. 17 (7) CDSM Directive.

${ }^{39}$ Art. 17(8) CDSM Directive. See, on this topic, Christina Angelopoulos and Martin Senftleben, 'An Endless Odyssey? Content Moderation Without General Content Monitoring Obligations' (IViR; CIPIL 2021) <https://papers.ssrn.com/abstract $=3871916>$ accessed 24 June 2021; Schwemer, 'Article 17 at the Intersection of EU Copyright Law and Platform Regulation' (n 28) 428.

${ }^{40}$ Art. 17(9) CDSM Directive.

${ }^{41}$ See arts. 288 and 290 of the Treaty on the Functioning of the European Union (TFEU).

${ }^{42}$ Guidance Art. 17 CDSM Directive (n.25), p. 1.

43 Opinion AG Øe in C-401/19, 15 July 2021, ECLI:EU:C:2021:613, para 223.

${ }^{44}$ Guidance Art. 17 CDSM Directive (n.25), p.23 (at fn 36).

${ }^{45}$ For an overview of YouTube's copyright content moderation technologies, see YouTube (n 20).

${ }^{46}$ See n. 22 and references cited therein.

${ }^{47}$ Spoerri (n 28).
} 
limitations ${ }^{48}$, leading to an conflict between different obligations within art. $17 .^{49}$ This conflict is explored below.

\section{2. $\quad$ Normative hierarchy of obligations and safeguards}

In light of the above, it is important to further explain the normative hierarchy embedded in art. 17 , as well as provide additional detail on its complaint and redress rules.

Art.17(7) includes a general and a specific clause on exceptions and limitations to copyright. The general clause is contained in the first sub-paragraph, which states that the obligations in 4(b) and (c) should not prevent that content uploaded by users is available on OCSSPs if such an upload does not infringe copyright, including if it is covered by an exception. ${ }^{50}$ The second paragraph of art. 17(7) CDSM Directive includes a special regime for certain exceptions and limitations: (i) quotation, criticism, review; (ii) use for the purpose of caricature, parody or pastiche. ${ }^{51}$ Additionally, art. 17(9) requires that OCSSPs inform users in their terms and conditions of the user's right to use works under exceptions. ${ }^{52}$

One key feature of the legal design of art. 17 is that paragraph (7) translates into an obligation of result. That is to say, Member States must ensure that these exceptions are respected despite the preventive measures in art. 17(4). This point matters because paragraph (4) merely imposes "best efforts" obligations. The different nature of the obligations, underscored by the fundamental rights-

\footnotetext{
${ }^{48}$ Under art. 17(7) CDSM Directive "Member States shall ensure that users in each Member State are able to rely on any of the following existing exceptions or limitations when uploading and making available content generated by users on online content-sharing services: (a) quotation, criticism, review; (b) use for the purpose of caricature, parody or pastiche."

${ }^{49}$ In this respect, see the excellent reporting by Paul Keller on the Commission Stakeholder Dialogues and their aftermath: Paul Keller, 'Article 17: (Mis)Understanding the Intent of the Legislator' (Kluwer Copyright Blog, 28 January 2021) <http://copyrightblog.kluweriplaw.com/2021/01/28/article-17-misunderstanding-the-intent-of-the-legislator/> accessed 4 May 2021; Paul Keller, 'Article 17 Stakeholder Dialogue: What We Have Learned so Far - Part 1' (Kluwer Copyright Blog, 13 January 2020) <http://copyrightblog.kluweriplaw.com/2020/01/13/article-17-stakeholder-dialoguewhat-we-have-learned-so-far-part-1/> accessed 7 May 2021; Paul Keller, 'Article 17 Stakeholder Dialogue: What We Have Learned so Far - Part 2' (Kluwer Copyright Blog, 14 January 2020) <http://copyrightblog.kluweriplaw.com/2020/01/14/article-17-stakeholder-dialogue-what-we-have-learned-so-far-part-2/> accessed 7 May 2021.

${ }^{50}$ This should be read in combination with the statement in Article 17(9) to the effect that the CDSM Directive "shall in no way affect legitimate uses, such as uses under exceptions or limitations provided for in Union law". In this respect, Recital 70 emphasizes the need for the preventive obligations to be implemented without prejudice to the application of exceptions and limitations, "in particular those that guarantee the freedom of expression of users". See João Pedro Quintais and others, 'Safeguarding User Freedoms in Implementing Article 17 of the Copyright in the Digital Single Market Directive: Recommendations from European Academics' (2020) 10 JIPITEC < https://www.jipitec.eu/issues/jipitec-10-3-2019/5042>.

${ }^{51}$ These were optional exceptions and limitations in arts. 5(3)(d) and (k) of the InfoSoc Directive, which have not been implemented in all Member States; where they have, the implementations differ.

52. Art. 17(9) para. 4 CDSM Directive.
} 
basis of paragraph $(7)^{53}$, indicates a normative hierarchy between the higher-level obligation in paragraph (7) and the lower-level obligation in paragraph (4). This matters not only for legal interpretation of art. 17 in general but also for the assessment of content moderation obligations in this legal regime. For instance, this legal understanding justifies the view that to comply with art. 17 it is insufficient to rely on ex post complaint and redress mechanisms in art. 17(9). It is also required to maintain $e x$ ante safeguards that avoid the overblocking of uploaded content by filtering content technologies used by OCSSPs that are incapable to carry out the type of contextual assessment required under art. 17(7). ${ }^{54}$

It is on this basis that Poland filed an action for annulment against art. 17 for failure to sufficiently safeguard the right to freedom of expression of users. ${ }^{55}$ In his Opinion, AG Saugmandsgaard Øe delineated the scope of permissible filtering of users' uploads. ${ }^{56}$ While acknowledging that OCSSPs will have to deploy filtering and content-recognition systems to comply with their best efforts obligations, the AG relies on the judgement in Eva Glawischnig-Piesczek to argue that any filtering must be "specific" to the content and information at issue, so as to not run afoul of the prohibition of general monitoring obligations in art. 15 e-Commerce Directive (and 17(8) CDSM Directive) ${ }^{57}$ However, such filtering must be proportionate and avoid the risk of chilling effects on freedom of expression through overblocking; in order to do so, it must be applied only to manifestly infringing or "equivalent" content. ${ }^{58}$ All other uploads should benefit from a

\footnotetext{
${ }^{53}$ See e.g., recital 70 CDSM Directive.

${ }^{54}$ See Quintais and others (n 47); Martin Husovec, 'Over-Blocking: When Is the EU Legislator Responsible?' (LSE 2021) Working Paper <https://papers.ssrn.com/abstract=3784149> accessed 4 May 2021; Christophe Geiger and Bernd Justin Jütte, 'Platform Liability Under Art. 17 of the Copyright in the Digital Single Market Directive, Automated Filtering and Fundamental Rights: An Impossible Match' [2021] GRUR International <https:/academic.oup.com/grurint/advance-article-abstract/doi/10.1093/grurint/ikab037/6169057?redirectedFrom=fulltext > accessed 4 May 2021. See also, agreeing with this interpretation, Guidance Art. 17 CDSM Directive (n. 25), pp. 2-3. See also supra at 2.1 and n. 49.

${ }^{55}$ Case C-401/19, Poland v Parliament and Council. Arguing that the Court should invalidate art. 17 on these ground, see Geiger and Jütte (n 51); Husovec (n 51). See also Case C-401/19, Poland v Parliament and Council, Opinion of Advocate General Saugmandsgaard Øe delivered on 15 July 2021, ECLI:EU:C:2021:613 (hereafter AG Opinion C401/19, Poland).

${ }^{56}$ Bernd Justin Jutte and Giulia Priora, 'On the Necessity of Filtering Online Content and Its Limitations: AG Saugmandsgaard Øe Outlines the Borders of Article 17 CDSM Directive' (Kluwer Copyright Blog, 20 July 2021) $<$ http://copyrightblog.kluweriplaw.com/2021/07/20/on-the-necessity-of-filtering-online-content-and-its-limitations-agsaugmandsgaard-oe-outlines-the-borders-of-article-17-cdsm-directive/> accessed 6 October 2021.

${ }^{57}$ AG Opinion C-401/19, Poland, paras 112-114 and 196, citing the Court's judgment in Case C-18/18, Eva GlawischnigPiesczek v Facebook Ireland Limited (3 October 2019), ECLI:EU:C:2019:821. On the topic of general monitoring obligations in the context of EU copyright law, see Angelopoulos and Senftleben (n 36); Christina Angelopoulos, 'YouTube and Cyando, Injunctions against Intermediaries and General Monitoring Obligations: Any Movement?' (Kluwer Copyright Blog, 9 August 2021) < http://copyrightblog.kluweriplaw.com/2021/08/09/youtube-and-cyando-injunctionsagainst-intermediaries-and-general-monitoring-obligations-any-movement/> accessed 5 October 2021.

${ }^{58}$ AG Opinion C-401/19, Poland, paras $196 \mathrm{ff}$. In this respect the Opinion deviates from and strongly criticizes the Commission's Guidance, which suggests a separate category of "earmarked content" susceptible of filtering, with lesser safeguards. See Id., para 223 (Postcriptum) and Guidance Art. 17 CDSM Directive (n.25), pp. 22-24. For criticism, see Julia Reda and Paul Keller, 'European Commission Back-Tracks on User Rights in Article 17 Guidance' (Kluwer
} 
"presumption of lawfulness" and be subject to the ex ante and ex post safeguards embedded in art. 17 , notably judicial review. ${ }^{59}$

In this respect, art. 17(9) further includes certain ex post or procedural safeguards at: (i) the platform level; (ii) the out-of-court level; and (iii) the judicial or court level. ${ }^{60} \mathrm{~A}$ few additional remarks are justified on the first two levels.

At the platform level, Member States are mandated to provide that OCSSPs "put in place an effective and expeditious complaint mechanism that is available to users of their services in the event of disputes over the disabling of access to, or the removal of, works or other subject matter uploaded by them". ${ }^{61}$ These mechanisms are further circumscribed insofar as complaints "shall be processed without undue delay, and decisions to disable access to or remove uploaded content shall be subject to human review". ${ }^{2}$ The latter human review-criterion implies that everything leading up to a dispute can be processed by the platform in an automated fashion by algorithms. ${ }^{63}$ It is further specified that these mechanisms should allow "users to complain about the steps taken with regard to their uploads, in particular where they could benefit from an exception or limitation

Copyright Blog, 4 June 2021) <http://copyrightblog.kluweriplaw.com/2021/06/04/european-commission-back-trackson-user-rights-in-article-17-guidance/> accessed 24 June 2021; Christophe Geiger and Bernd Justin Jütte, 'Towards a Virtuous Legal Framework for Content Moderation by Digital Platforms in the EU? The Commission's Guidance on Article 17 CDSM Directive in the Light of the YouTube/Cyando Judgement and the AG's Opinion in C-401/19' [2021] European International Property Review <https://papers.ssrn.com/abstract=3889049> accessed 17 August 2021.

${ }^{59}$ AG Opinion C-401/19, Poland, para 193.

${ }^{60}$ In this article, we do not examine the third level of safeguards in art. 17(9) CDSM Directive, relating to judicial authority or court level. See, e.g., Schwemer, 'Article 17 at the Intersection of EU Copyright Law and Platform Regulation' (n 28); Sebastian Schwemer and Jens Schovsbo, 'What Is Left of User Rights? - Algorithmic Copyright Enforcement and Free Speech in the Light of the Article 17 Regime' 17.

${ }^{61}$ Emphasis added. Note that the requirement is on Member States, compared to the ensuring of unavailability which is on the platforms. This first aspect resembles the Commission's original proposal from September 2016, where it suggested in art. 13(2) that 'Member States shall ensure that the service providers ... put in place complaints and redress mechanisms that are available to users in case of disputes over the application of the measures ... .', see Proposal for a Directive of the European Parliament and of the Council on copyright in the Digital Single Market $\operatorname{COM}(2016) 593$.

${ }^{62}$ Art. 17(9)(2), second sub-paragraph CDSM Directive (emphasis added). On a critique of the 'elastic timeframe' see Martin Senftleben, "Bermuda Triangle - Licensing, Filtering and Privileging User-Generated Content Under the New Directive on Copyright in the Digital Single Market"' (2019) 41 European Intellectual Property Review 480. In its Council vote, Germany suggests the timeframe to be understood "as rapidly as possible", see Draft Directive of the European Parliament and of the Council on copyright and related rights in the Digital Single Market and amending Directives 96/9/EC and 2001/29/EC (first reading), Statements, (Council of the European Union, 15 April 2019) $<$ https://data.consilium.europa.eu/doc/document/ST-7986-2019-ADD-1-REV-2/en/pdf > [Statement by Germany, point 7].

${ }^{63}$ See similarly Commission Recommendation (EU) 2018/334 of 1 March 2018 on measures to effectively tackle illegal content online, 6.3.2018, [2018] L 63/50, points 20 and 27 in relation to proactive measures on human oversight and in the context of data protection see, e.g., Article 22(3) Regulation (EU) 2016/679 of the European Parliament and of the Council of 27 April 2016 on the protection of natural persons with regard to the processing of personal data and on the free movement of such data, and repealing Directive 95/46/EC (General Data Protection Regulation). See also Schwemer, 'Article 17 at the Intersection of EU Copyright Law and Platform Regulation' (n 28); Schwemer and Schovsbo (n 57). 


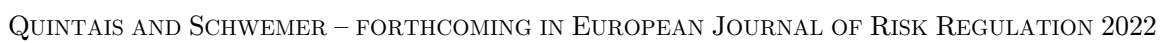

to copyright in relation to an upload to which access has been disabled or that has been removed". ${ }^{64}$

Furthermore, the provision stipulates a justification-duty on rights holders. The reasons for a rights holder's request to make content unavailable needs to be "duly justified" ${ }^{65}$ The decision at this level remains with the platform, but as Senftleben notes, "[t]he underlying legal assessment, however, is likely to be cautious and defensive (...) [and] a generous interpretation of copyright limitations serving freedom of expression seems unlikely, even though a broad application of the right of quotation and the parody exemption would be in line with CJEU jurisprudence." ${ }^{, 66}$ In other words, there is a risk of overenforcement. ${ }^{67}$

In addition to the platform-based procedural safeguards, also out-of-court redress mechanisms for the impartial settlement of disputes are to be put in place by Member States. ${ }^{68}$ This mechanism is "without prejudice to the rights of users to have recourse to efficient judicial remedies (...)." ${ }^{69}$ Specifically in relation to exceptions, "Member States shall ensure that users have access to a court or another relevant judicial authority to assert the use of" the same. ${ }^{70}$ Member States enjoy a considerable amount of discretion when implementing the procedural safeguards and such mechanisms might also be informed by the Commission Guidance on art. 17, which provides significant detail on how Member States may implement the safeguards paragraphs (7) and (9). ${ }^{71}$

\footnotetext{
${ }^{64}$ Recital 70 (emphasis added).

65. Article 17(9) sub-para. 2 CDSM Directive.

66. See Senftleben (n 59).

${ }^{67}$ For empirical work on overenforcement, see, e.g., Kris Erickson \& Martin Kretschmer, Empirical Approaches to Intermediary Liability, CREATe Working Paper 2019/6, (2019), pp. 10 ff.; Jennifer Urban, Joe Karaganis, \& Brianna Schofield, Notice and Takedown: Online Service Provider and Rightsholder Accounts of Everyday Practice, 64 Journal of the Copyright Society (2017); Sharon Bar-Ziv \& Niva Elkin-Koren, Behind the Scenes of Online Copyright Enforcement: Empirical Evidence on Notice \& Takedown, 50 Connecticut Law Review (2017); specifically in the context of YouTube and parodies, see Kris Erickson \& Martin Kretschmer, This Video Is Unavailable: Analyzing Copyright Takedown of User-Generated Content on YouTube, Journal of Intellectual Property, Information Technology and Electronic Commerce Law (2018) 9, 75 and Sabine Jacques et al., An Empirical Study of the Use of Automated AntiPiracy Systems and Their Consequences for Cultural Diversity, SCRIPTed (2018) 15(2), 277-312. For a recent overview of existing studies in this areas, see also Daphne Keller and Paddy Leerssen, 'Facts and Where to Find Them: Empirical Research on Internet Platforms and Content Moderation', Social Media and Democracy: The State of the Field and Prospects for Reform (Cambridge University Press 2019) < https://papers.ssrn.com/abstract=3504930> accessed 4 May 2021.

${ }^{68}$ Art. 17(9) sub-para. 2 CDSM Directive.

${ }^{69}$ Art. 17(9) sub-para. 2 CDSM Directive.

${ }^{70}$ Art. 17(9) sub-para. 2 CDSM Directive.

${ }^{71}$ Guidance Art. 17 CDSM Directive (n.25), pp. 18-25.
} 


\section{The interplay between the DSA and the CDSM Directive}

Against this background, the DSA proposal was published on 15 December 2020. The DSA is a regulation that is meant inter alia as "REFIT",72 of certain parts of the e-Commerce Directive. Other than the different legal nature of the proposed instrument - Regulation vs Directive - the DSA has a broader scope that the e-Commerce Directive ${ }^{73}$ and sets up a much more detailed procedural framework, which is further explored below. ${ }^{74}$

The proposed DSA is divided into five chapters: general provisions (I), liability of providers of intermediary services (II), Due diligence obligations for a transparent and safe online environment (III), Implementation, Cooperation, Sanctions and Enforcement (IV), and final provisions (V). For the purposes of this article, we are mostly concerned with Chapters I to III.

The liability exemptions in Chapter II largely resemble the system set forth 21 years ago in the e-Commerce Directive ${ }^{75}$, with notable adjustments such as a Good Samaritan clause ${ }^{76}$, clarifications on scope in recitals ${ }^{77}$, and provisions on orders: to act against illegal content; and to provide information. ${ }^{78}$ Separate from this, the proposal suggests the introduction of asymmetric due diligence obligations in Chapter III, which are a novelty compared to the e-Commerce Directive.

\subsection{Are rules on copyright excluded from the DSA?}

In this article, we are interested in the potential overlap between the proposed DSA and art. 17 CDSM Directive. This is visualized in the illustration below, which represents the overlaps between the concepts of online platforms, VLOPs and OCSSPs (Figure 2). Similar overlaps could be envisaged as regards the relationship of the DSA proposal's concepts with those of platforms used by providers in other sector-specific areas, such as "video-sharing platform service" in the

\footnotetext{
72 European Commission, REFIT - making EU law simpler, less costly and future proof, https://ec.eu$\underline{\text { ropa.eu/info/law/law-making-process/evaluating-and-improving-existing-laws/refit-making-eu-law-simpler-less-costly- }}$ and-future-proof_en.

${ }^{73}$ See art. 1 DSA proposal.

${ }^{74}$ See infra at 3.2.2.a).

${ }^{75}$ I.e., the specific liability exemptions for 'mere conduit', 'caching' and hosting remain largely unchanged.

${ }^{76}$ See, e.g., Aleksandra Kuczerawy, 'The Good Samaritan That Wasn't: Voluntary Monitoring under the (Draft) Digital Services Act' (Verfassungsblog, 12 January 2021) < https://verfassungsblog.de/good-samaritan-dsa/> accessed 5 May 2021.

${ }^{77}$ Sebastian Felix Schwemer, Tobias Mahler and Håkon Styri, 'Liability Exemptions of Non-Hosting Intermediaries: Sideshow in the Digital Services Act?' (2021) 8 Oslo Law Review 4.

${ }^{78}$ See arts 8 and 9 DSA proposal.
} 
Audiovisual Media Services Directive (AVMSD) ${ }^{79}$ and "hosting services" used for the dissemination to the public of terrorist content online Terrorist Content Regulation. ${ }^{80}$

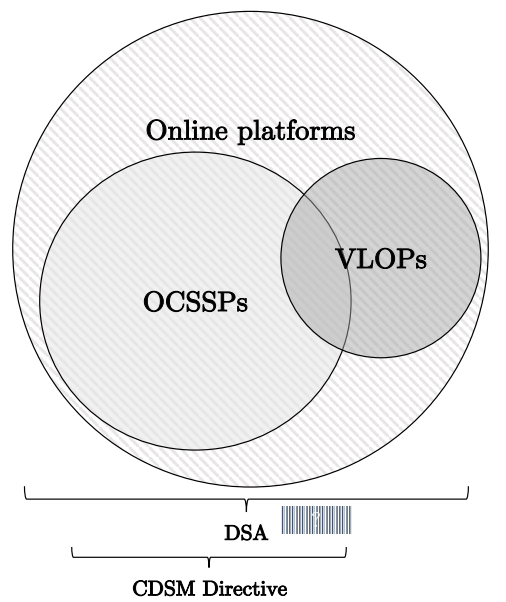

Figure 2. Overlap between DSA and CDSM Directive

A preliminary question for our purposes is whether the DSA applies to OCSSPs in the first place. Importantly, the special "copyright"-regime for OCSSPs only relates to the copyright-relevant portion of an online platform that qualifies as an OCSSP. Art. 17(3) subpara. 2 CDSM Directive states clearly that the hosting safe harbour of art. 14 e-Commerce Directive -and correspondingly that in art. 5 DSA- still applies to OCSSPs "for purposes falling outside the scope of this Directive." Consider the example of YouTube, which qualifies as OCSSP. If the relevant information or content it hosts relates to copyright, art. 17 CDSM Directive applies. If the relevant information, however, relates to hate speech or child sexual abuse material or any other illegal information or content ${ }^{81}$, the e-Commerce Directive's - and correspondingly DSA's - hosting liability exemption is the place to look. In other words, YouTube would be considered an OCSSP (in the context of copyright) and also a VLOP (in the context of other information). ${ }^{82}$

\footnotetext{
${ }^{79}$ Art. 1(1)(aa) AVMSD Directive 2010/13/EC, as amended by Directive (EU) 2018/1808 (AVMSD) ("')

${ }^{80}$ Arts 1 and 2 Regulation (EU) 2021/784 of the European Parliament and of the Council of 29 April 2021 on addressing the dissemination of terrorist content online (Text with EEA relevance) (Terrorist Content Regulation).

${ }^{81}$ Art. 2(g) DSA proposal defines "illegal content" as "'any information, which, in itself or by its reference to an activity, including the sale of products or provision of services is not in compliance with Union law or the law of a Member State, irrespective of the precise subject matter or nature of that law".

${ }^{82}$ See Figure 3 . In the context of the AVMSD, YouTube would qualify as a video-sharing platform service.
} 


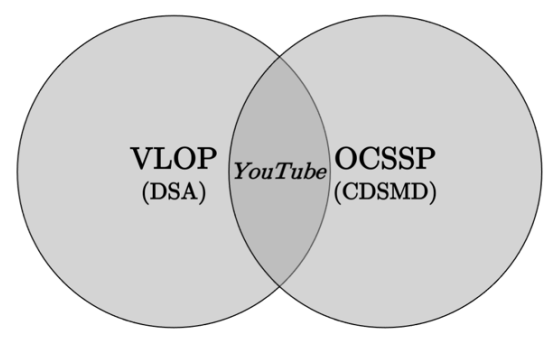

Figure 3. Example of overlap between regulatory regimes in the case of OCSSPS

In the following, we focus on the copyright aspects. Art. 1(5)(c) DSA states that the proposed Regulation is "without prejudice to the rules laid down by (...) Union law on copyright and related rights." Supporting Recital 11 adds that the "Regulation is without prejudice to the rules of Union law on copyright and related rights, which establish specific rules and procedures that should remain unaffected." Read alone, this Recital could be understood as the Commission's view that art. 17 CDSM Directive, in our example, indeed contains the answers to all questions regarding obligations of OCSSPs. In our view, however, "unaffected" ${ }^{1,3}$ can only relate to aspects which indeed are specifically covered by those rules.

Recital 11 (similar to Recital 10), however, is only a further example of areas of application of the general principle contained in Recital 9, aimed at providing further clarity on the interplay between the horizontal rules of the DSA and sector-specific rules. Recital 9 states that the DSA

"should complement, yet not affect the application of rules resulting from other acts of Union law regulating certain aspects of the provision of intermediary services (...). Therefore, this Regulation leaves those other acts, which are to be considered lex specialis in relation to the generally applicable framework set out in this Regulation, unaffected. However, the rules of this Regulation apply in respect of issues that are not or not fully addressed by those other acts as well as issues on which those other acts leave Member States the possibility of adopting certain measures at national level. ${ }^{\$ 4}$

The Explanatory Memorandum repeats this text and provides as one example the obligations set out in the AVMSD on video-sharing platform providers as regards audiovisual content and audiovisual commercial communications. It continues that such rules "will continue to apply" but that the DSA "applies to those providers to the extent that the AVSMD or other Union legal acts,

\footnotetext{
${ }^{83}$ Confusingly, the Explanatory Memorandum in one instance notes that "the proposal does not amend sector-specific legislation or the enforcement and governance mechanisms set thereunder, but provides for a horizontal framework to rely on, for aspects beyond specific content or subcategories of services regulated in sector-specific acts" (explanatory memorandum p. 6). The wording "amend" could suggest a broader exclusion than "unaffected". Since Recitals and articles of the proposal, however, do not take this up, we refrain from further analysis.

${ }^{84}$ Recital 9 DSA Proposal (our emphasis).
} 
such as the proposal for a Regulation on addressing the dissemination on terrorist content online, do not contain more specific provisions applicable to them. ${ }^{, 85}$

Applying this logic to the CDSM Directive, this means that the specific rules and procedures contained in art. 17 for OCSSPs are likely considered lex specialis to the DSA. ${ }^{86}$ Conversely, the DSA will apply to OCSSPs insofar as it contains: (i) rules that regulate matters not covered by art. 17 CDSM Directive; and (ii) specific rules on matters where art. 17 leaves margin of discre$\operatorname{tion}^{87}$ to Member States. As we demonstrate below, whereas category (i) is more or less straightforward, category (ii) is more challenging. In our view, the changes proposed to the DSA provisions examined above on the relationship between the copyright acquis and the DSA during the legislative process (by the Council and different EP committees) do not affect the validity of our conclusions. ${ }^{88} \mathrm{~A}$ similar conclusion appears valid for other types of illegal content.

\subsection{Potentially applicable rules}

At this stage, it is important to note that the DSA contains a bifurcated approach to regulation. On the one hand, Chapter II sets out a regime for the liability of providers of intermediary services. ${ }^{89}$ This regime distinguishes between functions, namely 'mere conduit', 'caching' and hosting. It is in essence a revamped version of the existing rules on liability exemption (also known as safe harbours) and ban on general monitoring in arts. 12 to 15 e-Commerce Directive. ${ }^{90}$ The main differences are the addition of a "Good Samaritan"-like rule in art. 6 "1 , and provisions on orders to act against illegal content (art. 8) and to provide information (art. 9). On the other hand, Chapter III sets out "horizontal",92 due diligence obligations for a transparent and safe online environment. ${ }^{93}$ This regime distinguishes between categories of providers, by setting out asymmetric obligations that apply in a tiered way to different categories of providers of information society

\footnotetext{
${ }^{85}$ Unfortunately, the Explanatory Memorandum refrains from specifically addressing its relation to the CDSM Directive. Since the AVMS Directive explicitly only serves as one example, however, there is no indication that this general principle would not apply to other specific rules.

${ }^{86}$ One could also reflect upon the chronological order of the legislative acts in the vein of a lex posteriori derogate (legi) priori interpretation. However, since the CDSM Directive was only adopted as late as April 2019 and since there is no indication of such intention in the preparatory works, we refrain from further exploring this perspective.

${ }^{87}$ A different set of questions, notably around primacy of EU law, would arise if Member States lack that discretion.

${ }^{88}$ See, reaching the same conclusion, Peukert and others (n 11) 3-4. See, in particular, the IMCO Draft European Parliament Legislative Resolution, EP Document A9-0356/2021 (proposed Amendment 11 to Recital 11, according to which the DSA is without prejudice to the CDSM Directive, since the directive "establish[es] specific rules and procedures that should remain unaffected").

${ }^{89}$ See arts. 3 to 9 DSA proposal.

${ }^{90}$ See also art. 71 DSA proposal.

${ }^{91}$ On which, see Kuczerawy (n 73). (noting that the provision "aims to eliminate existing disincentives towards voluntary own-investigations undertaken by internet intermediaries" but that "it is questionable whether facilitating more voluntary removals is actually beneficial from the perspective of users and their right to freedom of expression.")

${ }^{92}$ Cf. Recital 73 DSA proposal.

93 arts. 10 to 37 DSA proposal.
} 


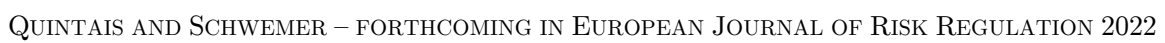

services. As a starting point, the liability exemption regime, on the one hand, and the due diligence obligations, on the other hand, are separate from each other. In other words: the availability of a liability exemption is not dependent on compliance with due diligence obligations and vice-versa. ${ }^{94}$

In this respect, the DSA retains in art. 2(a) the definition of 'information society services' of the e-Commerce Directive that underpins the notion of information society service provider (ISSP). For the purposes of due diligence obligations, it then proposes a distinction between four categories of services, from general to increasingly more specific: (1) intermediary services, (2) hosting services, (3) online platforms, and (4) very large online platforms (VLOPs). ${ }^{95}$ These are visualised in Figure 4 below.

Intermediary services, the broadest category, comprises "mere conduit", "caching", or hosting services. ${ }^{96}$ Hosting services consist "of the storage of information provided by, and at the request of, a recipient of the service“. ${ }^{97}$ Online platforms are defined as providers of "a hosting service which, at the request of a recipient of the service, stores and disseminates to the public information, unless that activity is a minor and purely ancillary feature of another service and, for objective and technical reasons cannot be used without that other service, and the integration of the feature into the other service is not a means to circumvent the applicability of this Regulation. ${ }^{, 98}$ In simple terms, VLOPs are those online platforms that provide their services to a number of average monthly active recipients of the service in the EU equal to or higher than 45 million, i.e. representing $10 \%$ of the European population. ${ }^{99}$ In practical terms, only the major user-upload Big Tech platforms operating in the current digital ecosystem - such as YouTube, Facebook or Instagram - would qualify as VLOPs. ${ }^{100}$ Under the asymmetric obligations approach of Chapter III DSA, VLOPs are subject to the highest number of cumulative obligations. ${ }^{101}$ This is justified by the "systemic role" played by such platforms in "amplifying and shaping information flows online", and by the fact that "[t]heir design choices have a strong influence on user safety online, the shaping of public opinion and discourse, as well as on online trade". ${ }^{102}$

\footnotetext{
${ }^{94}$ Note, however, e.g. Art.14(3) DSA proposal ("Notices that include the elements referred to in paragraph 2 shall be considered to give rise to actual knowledge or awareness for the purposes of Article 5 in respect of the specific item of information concerned.")

${ }^{95}$ Art. 1(f) and 25 DSA proposal.

${ }^{96}$ art. 2(f) DSA Proposal.

${ }^{97}$ Similar to the current wording of the e-Commerce Directive's art. 14.

98 art. 2(h) DSA Proposal.

99 Art. 25 DSA Proposal.

${ }^{100}$ See e.g. the number of average users in the EU for these platforms reported in: DSA Impact Assessment - Part 2/2 (Brussels, 15.12.2020) SWD(2020) 348 Final, pp. 64-65. In other words, whereas many online platforms might qualify as OCSSP under the CDSMD (e.g., TikTok, Twitter, Reddit, or Pornhub) their qualification as VLOPs under the DSA depends on the number of recipients of the service

${ }^{101}$ Arts. 25-33 DSA proposal. For a visual representation, see European Commission, The Digital Services Act: ensuring a safe and accountable online environment, New Obligations, https://ec.europa.eu/info/strategy/priorities-20192024/europe-fit-digital-age/digital-services-act-ensuring-safe-and-accountable-online-environment en

${ }^{102}$ DSA Impact Assessment, Part 1/2 (Brussels, 15.12.2020) SWD(2020) 348 Final, p.12.
} 
In our view, when contrasting the definitions in the DSA and CDSM Directive, it is clear that the notion of OCSSP covers at least (certain) online platforms and VLOPs, as represented in Figure 4.

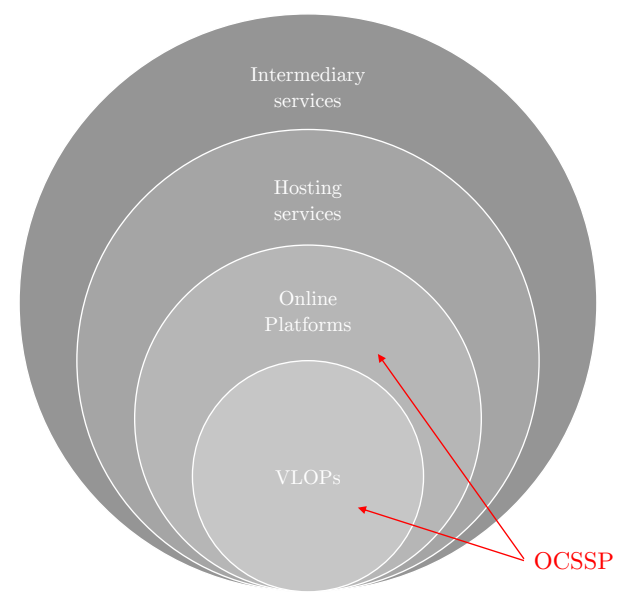

Figure 4. DSA typology of ISSP and placement of OCSSPS ${ }^{103}$

In light of this overlap, the legal question that arises is to what extent the proposed DSA's liability rules (in Chapter II) and the asymmetric obligations (in Chapter III) apply to OCSSPs as online platforms or VLOPs. Although the analysis below focuses on copyright, it provides a blueprint for a similar examination of the DSA liability regime and obligations would apply to other sectorspecific instruments. For instance, it could help shed light on the articulation of the DSA with the AVMSD, which already imposes certain obligations on video-sharing platform services to protect minors and EU citizens from certain categories of illegal and harmful content ${ }^{104}$, while attaching "cooperative responsibility to [those] platforms' organisational control". ${ }^{105}$

\subsubsection{DSA Liability Regime and OCCSPs}

In our view, the liability regime in the DSA is partly excluded for OCSSPs. First, the hosting safe harbour (in art. 5 DSA) is meant to replace art 14 e-Commerce Directive. ${ }^{106}$ As such, its

\footnotetext{
${ }^{103}$ Figure 4 is an adjustment by the authors of a similar figure available at European Commission, The Digital Services Act: ensuring a safe and accountable online environment, Which providers are covered, https://ec.europa.eu/info/strategy/priorities-2019-2024/europe-fit-digital-age/digital-services-act-ensuring-safe-and-accountable-online-environment_en ${ }^{104}$ Arts 28a and 29a AVMSD.

${ }^{105}$ MZ van Drunen, 'The Post-Editorial Control Era: How EU Media Law Matches Platforms' Organisational Control with Cooperative Responsibility' (2020) 12 Journal of Media Law 166.

${ }^{106}$ See art. 71 DSA proposal.
} 
Quintais AND SCHWEMER - FORThCOMING IN EUROPEAN JouRNAL OF RiSk ReGUlation 2022

application is set aside by the express reference in art. 17(3) CDSM Directive, to the extent that the activities at issue fall within the scope of art. 17 CDSM Directive. ${ }^{107}$

The general monitoring ban in art. 7 DSA, which aims to replace the similar prohibition ${ }^{108}$ in art. 15 e-Commerce Directive, on the other hand, appears to not be touched by the CDSM Directive. Art. 17(8) CDSM Directive merely states that "[t]he application of this Article shall not lead to any general monitoring obligation." It does not set aside the application of art. 15 e-Commerce Directive, meaning that it can be understood as being of a merely declaratory nature. ${ }^{109}$

Things are, however, less clear for the "good Samaritan" rule in art. 6 DSA on "[v]oluntary owninitiative investigations and legal compliance". Given the direct reference to the liability exemptions in the DSA, its application appears to be directly connected (for our purposes) to the specific hosting safe harbour, which does not apply to OCSSPs as per art. 17(3) CDSM Directive. In a narrow reading, this direct connection could be interpreted as precluding art. 6 DSA's application in the context of OCSSP. This exact issue will resurface below when we examine due diligence obligations. There may, however, exist good arguments for not taking direct references to the DSA's liability exemptions as evidence for precluding their applicability, which we explore in detail below. ${ }^{110}$

In the specific context of art. 6 DSA, in any case, the applicability on OCSSPs is further complicated: Art. 6 DSA is meant to enable "activities aimed at detecting, identifying and removing, or disabling of access to, illegal content, or take the necessary measures to comply with the requirements of Union law, including those set out in this Regulation." But art. 17(4)(b) and (c) CDSM Directive already set forth a liability exemption mechanism requiring OCSSPs make best efforts to apply preventive measures to ensure the unavailability or removal of copyright infringing content. These specific rules for OCSSPs would appear to leave little space for voluntary own-initiative investigations by online platforms, and consequently the application of art. 6 DSA. As a result, there may be no need to look for interpretations that would include voluntary activities by OCCSPs. ${ }^{111}$

Yet, it is conceivable that certain voluntary measures by OCSSPs could go beyond the required "best efforts", and would therefore not trigger liability, provided they are within the limits imposed by art. 17(7)-(9) CDSM Directive. This is particularly true in light of the different nature of the instruments at issue (Regulation vs Directive) and the potential for diverging national

\footnotetext{
${ }^{107}$ See supra at 2. NB that activities of certain online platforms that host copyright-protected materials but do not qualify as OCSSPs will still potentially benefit from the safe harbour in art. 14 e-Commerce Directive / art. 5 DSA.

${ }^{108}$ A further analysis of the differences between art. 7 DSA proposal and art. 15 e-Commerce Directive is outside the scope of this paper.

${ }^{109}$ See supra at 2.1 and Schwemer, 'Article 17 at the Intersection of EU Copyright Law and Platform Regulation' (n 28). Generally on the topic and with further interpretations, see Angelopoulos and Senftleben (n 36).

${ }^{110}$ See below at $3.2 .2 \mathrm{a}$ ).

111 This may be different in other sector-specific legislation, which is outside the scope of this paper.
} 
implementations and interpretations of the concepts of "best efforts" in art. 17(4), as already manifested during the implementation process. ${ }^{112}$ This problem of multi-layered geographically dispersed enforcement is not necessarily solved by the Commission's Guidance either. For instance, when discussing best efforts to obtain an authorization (a pre-condition for the liability exemption) in art. 17(4)(a), the Commission identifies scenarios, sectors and players in relation to which OCSSPs must proactively seek a license or react to offered licenses. But despite copyright being a territorial right, the geographical scope of a platform's obligation is far from clear. What is more, the Commission falls back to the conclusion that this obligation should be assessed on a "case-bycase" basis. ${ }^{113}$ In other words, there is a likelihood for legal uncertainty arising out of the diverse national implementations and practices of preventive measures by platforms for copyright infringing content pursuant to the Directive, as compared to the horizontal EU wide obligations stemming from the DSA. Given the potential complexity arising out of this legal puzzle, it would be important to clarify this relationship during the legislative process. This point has practical consequences for how platforms can and should design their content moderation systems in light of both the DSA and the CDSM Directive.

Finally, the rules on orders against illegal content and orders to provide information in arts. 8 and 9 DSA may apply to OCSSPs. Art. 8 DSA, in particular, sets out a detailed regime not available elsewhere to OCSSPs. To be sure, one could argue that art. 8(3) InfoSoc Directive, as interpreted by the CJEU, already provides specific rules on injunctions. But the latter provision applies only to "intermediaries whose services are used by a third party to infringe a copyright or related right", a rule consistent with art. $14(3)$ e-Commerce Directive. ${ }^{114}$ In other words, art. 8(3) InfoSoc Directive applies to intermediaries that are not directly liable for the content they host. This is not the case of OCSSPs, who by virtue of the legal regime in art. 17(1) CDSM Directive are directly liable for the content they host and is publicly available. If that is the case, then it would seem that art. 8 DSA applies to OCSSPs, opening the thorny question as to the applicability to this new reality of the extensive CJEU case law on the intersection between fundamental rights, copyright enforcement against intermediaries, and the prohibition on general monitoring. ${ }^{115}$

\footnotetext{
112 Aline Larroyed, 'When Translations Shape Legal Systems: How Misguided Translations Impact Users and Lead to Inaccurate Transposition - The Case of "Best Efforts" Under Article 17 DCDSM' (Institute for Globalization and International Regulation Maastricht University 2020) Study $<$ https: / papers.ssrn.com/abstract $=3740066>$ accessed 14 July 2021. See also Guidance Art. 17 CDSM Directive (n.25), advancing multiple possible interpretations of the concepts of best efforts in art. 17(4).

${ }^{113}$ See Guidance Art. 17 CDSM Directive (n.25), pp. 9-11 (section V.1). For a critical analysis, see João Pedro Quintais, 'Commission's Guidance on Art. 17 CDSM Directive: The Authorisation Dimension' (Kluwer Copyright Blog, 10 June 2021 ) <http://copyrightblog.kluweriplaw.com/2021/06/10/commissions-guidance-on-art-17-cdsm-directive-the-authorisation-dimension/> accessed 7 October 2021.

114 Art. 14(3) e-Commerce Directive states the hosting safe harbour "shall not affect the possibility for a court or administrative authority, in accordance with Member States' legal systems, of requiring the service provider to terminate or prevent an infringement, nor does it affect the possibility for Member States of establishing procedures governing the removal or disabling of access to information."

${ }^{115}$ On which, see Martin Husovec, Injunctions against Intermediaries in the European Union: Accountable but Not Liable? (Cambridge University Press 2017); Christina Angelopoulos, European Intermediary Liability in Copyright: A Tort-Based Analysis (Kluwer Law International 2016); Angelopoulos and Senftleben (n 36); Angelopoulos (n 54).
} 


\subsubsection{What due diligence obligations for OCSSPs?}

It is outside the scope of this paper to discuss in depth all potential obligations that apply to online platforms and VLOPs in the proposed DSA. Instead, we will focus on selected key obligations that apply to both categories and might be relevant for OCSSPs. This includes certain due diligence obligations for all providers of intermediary services (arts. 10-13), online platforms (arts. 14-24) and VLOPs (arts. 25-33). ${ }^{116}$ In our view, these are also likely to be in practice some of the provisions that may impose additional obligations to providers subject to other sector specific rules, such as video-sharing platforms in the AVMSD and hosting service providers in the Terrorist Content Regulation.

As a preliminary remark, we see no obstacle to the application to OCSSPs of general obligations ${ }^{117}$ that extend all intermediary services on points of contact, legal representatives, terms and conditions $^{118}$, and transparency reporting. This includes the obligations set out in arts. 10 to 13 (with aggravation in arts. 23, and 33 DSA). Furthermore, since art. 17 CDSM Directive focuses on the disabling of illegal information and not the recommendation or promotion of information, the relevant rules in the DSA on recommender systems (art. 29) should also fully apply to OCCSPs. ${ }^{119}$ This conclusion, we note, would be valid for other sector-specific legislative instruments in EU law that regulate only certain content moderation activities by service providers (e.g. concrete aspects of notice-and-action) but not recommender systems.

As noted in our introduction, private ordering via terms and conditions and automated content moderation systems is a crucial component of platform power, especially as concerns Big Tech platforms. In this regard, art. 12 DSA is particularly noteworthy. ${ }^{120}$ This provision applies to all intermediary service providers: it aims to increase the transparency of intermediaries' terms and conditions and bring their enforcement in direct relation to fundamental rights. ${ }^{121}$ In the

\footnotetext{
${ }^{116}$ We do not discuss here the exclusion, in art. 16 DSA, of micro and small enterprises from the additional obligations imposed on online platforms in Section 3 of Chapter 3 DSA. In this connection, it is noteworthy that art. 17(6) CDSM Directive contains a special regime for small and new OCSSPs, with mitigated obligations but no exclusion. On this regime and its interpretation, see also Guidance Art. 17 CDSM Directive (n.25), pp. 16-17.

${ }^{117}$ Chapter III, Section 1 DSA proposal, with certain further adjustments of the obligations for specific intermediary services.

118 Art. 12 DSA obliges intermediary service inter alia to provide information on content moderation including algorithmic decision making and human review. Art. 19(9) subpara. 4 CDSM Directive, too, stipulates a duty on OCSSPs to inform in users in their terms and conditions, however, only with respect to the possibility to use copyright-protected works under copyright limitations and exceptions provided for in the copyright acquis.

${ }^{119}$ See art. 29 DSA proposal (and subsequent amendments by Parliament). See also Sebastian Felix Schwemer, 'Recommender Systems in the EU: From Responsibility to Regulation' (2022) 1 Morals \& Machines.

${ }^{120}$ We refer in this paragraph to the Commission's proposal version of art. 12 DSA. Although the provision has been subject to amendments in both the Council and EP versions, the core obligations we examine remain intact.

${ }^{121} \mathrm{NB}$ art. 12 DSA applies not only to illegal content but also to harmful content, as defined in the terms and conditions of an intermediary.
} 


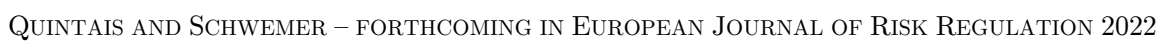

Commission's proposal, Art. 12(1) DSA imposes an information obligation regarding restrictions imposed on users of intermediary services, which obligation extends to algorithmic decision-making. Art. 12(2) DSA then introduces an apparently broad obligation for providers to act in a diligent, objective and proportionate manner when applying and enforcing such restrictions, explicitly linked to the respect of fundamental rights. Furthermore, the provision expands the scope of the obligations beyond illegal content, applying also to content which intermediaries consider harmful or undesirable in their terms and conditions. These horizontal obligations for all providers of intermediary services are welcome, especially as a means to curtail the private ordering power of Big Tech platforms (particularly VLOPs) as well as less visible intermediaries. ${ }^{122}$ However, because the obligations appear too vague as to be effective, there are doubts whether this provision will be relevant to curtail the power of platforms in defining the terms of their relationship with users, including how they operationalize their algorithmic content moderation systems. ${ }^{123}$ Despite these shortcomings, there is undoubtedly some value added in the application of art. 12 DSA to OCSSPs. The reason is that art. 17 CDSM Directive is remarkably thin in this respect. In fact, art. 17(9) merely requires that OCSSPs inform users in their terms and conditions of the user's right to use works under exceptions, with the Commission Guidance adding precious little in this respect. $^{124}$

a) Notice-and-action and statement of reasons ${ }^{125}$

A trickier question is whether or not the detailed regimes on notice-and-action (art. 14) and statement of reasons (art. 15) are suggested to apply to OCSSPs.

As explained above, art. 17(4)(b) and (c) CDSM Directive set out a specific notice-and-action regime, which includes in paragraph (c) obligations regarding notice-and-takedown as well as notice-and-stay-down. ${ }^{126}$ This could point in the direction of the DSA being excluded here, since the copyright sector-regulation contains rules on the matter. At the same time, however, art. 17 CDSM Directive remains vague around the concrete notice-and-action setup: it merely mentions

\footnotetext{
122 See Schwemer, Mahler and Styri (n 74).

${ }^{123}$ For criticism, see Appelman, Quintais and Fahy, 'Article 12 DSA' (n 16); Appelman, Quintais and Fahy, 'Using Terms and Conditions to apply Fundamental Rights to Content Moderation' (n 16); Alexander Peukert, 'Five Reasons to be Skeptical About the DSA' (Verfassungsblog) < https://verfassungsblog.de/power-dsa-dma-04/> accessed 8 October 2021. It is, for example, unclear whether art. 12(2) DSA would require some kind of fundamental rights impact assessment by the respective intermediaries.

${ }^{124}$ On this point, the Commission's Guidance merely suggests that "Member States could give recommendations on how service providers can increase users' awareness of what may constitute legitimate uses", for example through the provision of "accessible and concise information on the exceptions for users, containing as a minimum information on the mandatory exceptions provided for in Article 17". See Guidance Art. 17 CDSM Directive 90

(n.25), p.26, adding: "Besides providing this information in the general terms and conditions of the service providers, this information could be given in context of the redress mechanism, to raise the awareness of users of possible exceptions or limitations that can be applicable."

${ }^{125}$ Chapter III, Section 2 DSA proposal.

${ }^{126}$ See supra at 2.
} 
Quintais AND SCHWEMER - FORThCOMING IN EUROPEAN JouRNAL OF RiSk ReGUlation 2022

"a sufficiently substantiated notice" that must originate from rightsholders. ${ }^{127}$ In a vacuum, this would for instance allow Member States margin of discretion in regulating the details of such notice. In that line, the recent Commission Guidance on art. 17 advances concrete recommendations on the content of such notice, most notably that it follows the 2018 Recommendation on Measures to Effectively Tackle Illegal Content Online. ${ }^{128}$

Thus, it is also arguable that some components of the notice-and-action regime, such as the minimum elements that should be contained in a notice to a platform ${ }^{129}$, add a level of specificity not found in the lex specialis rules of the CDSM Directive. ${ }^{130}$ Then again, already today the European landscape for notices is varying, since some Member States chose to amend the implementation of the hosting liability exemption in art. 14 e-Commerce Directive with procedural rules, whereas others did not. On this point, it is important to remember that the very choice of instrument for the DSA -a Regulation vis-à-vis Directive- was considered necessary to provide legal certainty, transparency and consistent monitoring. ${ }^{131}$ Furthermore, the accompanying Explanatory Memorandum points out that sector-specific instruments do not cover all regulatory gaps, especially with regards to "fully-fledged rules on the procedural obligations related to illegal content and they only include basic rules on transparency and accountability of service providers and limited oversight mechanisms". ${ }^{132}$ Similarly, art. 1(2)(b) DSA notes that the aim of the Regulation is to set out uniform rules. All these considerations suggest the application of DSA rules to OCSSPs.

Against this application, the strongest argument we find lies with the nature of the legal instrument and the consideration that the rationale for the vaguer regime of art. 17 CDSM Directive in this regard was precisely to allow some margin of discretion to platforms and rights holders on how to define the content of notices for the specific subject matter of copyright. In that line, such a margin would be more adequately filled by national implementations pursuant the recommendations of the Commission Guidance, rather than by application of the DSA. ${ }^{133}$

But there an inherent tension (if not contradiction) in this argument, between allowing for the margin of discretion at national level inherent to the nature of a Directive and the desire to claw back much of that discretion via the Commission's extensive Guidance on art. 17. In fact, the

\footnotetext{
${ }^{127}$ See art. 17(4)(c) CDSM Directive. In this respect art. 17 clearly requires that the notice must originate from the rights holder (and presumably its representative), which is marked difference from art. 14(1) DSA proposal. The latter allows "any individual or entity to notify [hosting service providers] of the presence on their service of specific items of information that the individual or entity considers to be illegal content". In our view, given the private right nature of copyright and the specific requirement in art, 17(4) CDSM Directive, only rightsholders or those entitled to act on their behalf (e.g., pursuant to art. 5 Enforcement Directive) would be able to make notifications to service providers regarding copyright infringement, even if portions of art. 14 CDSM Directive apply to OCSSPs.

${ }^{128}$ Guidance Art. 17 CDSM Directive (n.25), pp. 15-16 (referring to points 6-8 of the Recommendation).

${ }^{129}$ Art. 14(2) DSA proposal.

${ }^{130}$ See also Peukert and others (n 11) $4-5$.

131 Explanatory memorandum, DSA proposal p. 7.

${ }^{132}$ Explanatory memorandum, DSA proposal p. 4.

${ }^{133}$ See Guidance Art. 17 CDSM Directive (n.25), pp. 15-16.
} 
Guidance aims not only at a legally "coherent and consistent" transposition of the provisions across the EU but also at assisting "market players" in complying with national laws in this area. ${ }^{134}$ To this effect, for instance, the Commission identifies standards for content recognition tools for different types of providers, incentivizes standardization of reporting information, encourages the development of registries of rights holders and protected content, and establishes rules and thresholds for what types of content may and may not be subject to filtering measures. ${ }^{135}$ In other words, the Guidance enables both a much more uniform implementation of art. 17 obligations by Member States and allows OCSSPs - especially those larger platforms that qualify as VLOPs - to provide identical offers across the EU in compliance with art. 17. For instance, in the case of YouTube, it would be more sensible to adjust its EU-wide services and systems (e.g. ContentID and Copyright Match Tool and Webform) to apply consistently on a cross-border basis and ensure compliance with the most developed and sophisticated national implementation of art. 17, which would likely be German law. ${ }^{136}$ The important consequence of this development, for our purposes, is that it facilitates an alignment of the horizontal DSA rules, particularly those applicable to VLOPs, with sector specific copyright rules, going some way into addressing the multi-layered enforcement problem arising from the overlapping obligations for platforms stemming from a Directive vs a Regulation.

In any case, the definite answer to the question on the application of art. 14 DSA to OCSSPs also depends on the legal nature of the provision: is it to be understood as supplement to the specific hosting liability exemption in art. 5 DSA or as due diligence obligation applicable to hosting services more broadly? On the one hand, it is clear that due diligence obligations are to be seen as separate from liability exemptions. The (non-)compliance with due diligence obligations does not affect the hosting safe harbour, and vice-versa. On the other hand, this distinction between safe harbours and due diligence obligations is blurred by the -we think problematic and probably unintended- effect a notice is suggested by the Commission's proposal to have on the actual knowledge of a hosting service. ${ }^{137}$ Since art. 14(3) DSA makes direct reference to the hosting liability exemption in art. 5 DSA, at least paragraph (3) of art. 14 DSA may not be directly apply to OCSSPs.

A similar reasoning applies to the rules on statement of reasons (art. 15 DSA), which apply to the justification provided by platforms to users regarding decisions to remove or disable access to specific items of information. In the scheme of art. 17 CDSM Directive, users appear to be informed about these reasons only through a complaint and redress mechanism. Under art. 17(9), rights holders "shall duly justify the reasons for their [removal] requests" to OCSSPS, who will then take

\footnotetext{
${ }^{134}$ See Guidance Art. 17 CDSM Directive (n.25), p.1.

${ }^{135}$ Guidance Art. 17 CDSM Directive (n.25).

${ }^{136}$ On YouTube's general approach in this regard, see Marco Pancini, 'YouTube's Approach to Copyright' (Google, 31 August 2021) <https://blog.google/around-the-globe/google-europe/youtubes-approach-to-copyright/> accessed 14 October 2021. On the German implementation act, see BJfV, Aktuelle Gesetzgebungsverfahren, Act on the Copyright Liability of Online Content Sharing Service Providers (Urheberrechts-Diensteanbieter-Gesetz - UrhDaG), 14 June 2021, https://www.bmjv.de/SharedDocs/Gesetzgebungsverfahren/Dokumente/UrhDaG_ENG.html?nn=6712350 .

${ }^{137}$ See art. 14(3) DSA proposal.
} 
Quintais AND SCHWEMER - FORThCOMING IN EUROPEAN JouRNAL OF RiSk ReGUlation 2022

a decision on removal or disabling. There are no explicit rules on whether, when, and how these decisions are communicated to users, which suggests that there is ample margin for application of the specific rules set out in art. 15 DSA. In practice, this would mean that platforms would have to extend their reporting systems in this regard for other types of illegal content also to copyright infringing content.

\section{b) Internal complaint mechanism and out-of-court dispute settlement}

In the context of online platforms, arts. 17 and 18 DSA set forth a detailed internal complaint mechanism as well as out-of-court dispute settlement. Art. 17 CDSM Directive also mandates such mechanisms in paragraph (9) for the specific genus of OCSPPs, but in a much less detailed fashion. In various forms, both the DSA and art. 17 CDSM Directive stipulate that such internal complaint mechanisms need to be effective, processed within a reasonable timeframe (undue delay/timely manner), and involve some form of human review. The DSA, however, is more detailed and includes, for instance, a requirement of user-friendliness and a minimum period for filing such complaint of six months following the takedown decision.

The question is, thus, again whether the DSA is able or intended to "fill" the holes that the lex specialis-regulation in the CDSM Directive left open. First, however, even if answered in the negative, it could be argued that arts. 17 and 18 DSA - in the view of the EU-lawmaker - represent the archetypes of "effective and expeditious" mechanisms. Complaint and redress mechanisms should therefore be modelled after the horizontal DSA example where the CDSM Directive falls short. In our view, this is a normatively desirable outcome in line with the aims of the DSA. ${ }^{138}$

Second, we should not forget that OCSSPs are not relevant from a copyright-perspective only. If a video on YouTube contains illegal hate speech, the notice-and-action mechanism (and following redress mechanisms) would not fall under the regime of art. 17 CDSM Directive but rather that of the e-Commerce Directive and future DSA. ${ }^{139}$ Having various similar but different redress mechanisms for the very same platform depending only on the legal regime governing the content at issue (copyright, personal data, hate speech, etc.) can hardly be in the interest of the lawmaker ${ }^{140}$, OCSSPs, internet users or other stakeholders. This strongly argues in favor of the application of the DSA rules consistently to all platforms.

This is especially true for Big Tech platforms, who have developed complex complaint and redress mechanisms as part of their content moderation systems for different types of illegal and harmful content with the result of obfuscating users' ability to obtain effective redress for their

\footnotetext{
${ }^{138}$ See, in this respect, the proposals in Peukert and others (n 11) 14.

${ }^{139}$ Another related question is what framework would apply if one and the same video is relevant from a copyrightperspective and a non-copyright perspective; e.g., a parody of a copyright-protected work that also contains hate speech. ${ }^{140} \mathrm{See}$, e.g., recitals 4 and 7 DSA proposal.
} 
complaints. ${ }^{141}$ In particular for copyright infringing content, the systems put in place by larger platforms like YouTube have meant in practice that complaint and redress mechanism are rarely used by users. ${ }^{142}$ In this regard, it is noteworthy that art. 17 CDSM Directive lacks some of the DSA safeguards, such as the presence of a body like the Digital Services Coordinator and a clear obligation of reinstating content in art. 17(3) DSA as a countermeasure to over-blocking. ${ }^{143}$ Combined with a limitation of filtering measures to "manifestly infringing content" endorsed by the Commission Guidance on art. 17 and the AG in Case C-401/19 ${ }^{144}$, these overlapping obligations of the DSA and the Directive would better protect the freedom of expression of users by influencing platforms' design of these mechanisms, adding external oversight, and increasing users in-platform redress avenues. ${ }^{145}$

A counter argument would be that such differentiated approach is justified in light of the specific character of the rights concerned. The question then is: What part of substantive copyright law would prescribe a different treatment for the complaint handling of copyright-related content takedowns? The immediate starting point for such special place for copyright in the heart of the EU acquis would be its protection in art. 17(2) Charter of Fundamental Rights of the European Union $^{146}$ and the high-level of protection as set out in the recitals of the InfoSoc Directive and emphasized time and again by the CJEU. ${ }^{147}$ In our view, however, that high-level protection can hardly be undermined by safeguarding complaint mechanisms. The latter only become relevant once content has been taken down and a potential infringement of the protected rights is prevented. Instead, redress mechanisms relate inter alia to users' fundamental rights (vis-à-vis a platform's right to conduct a business). Consequently, we argue that arts. 17 and 18 DSA should apply to OCSSPs to fill the gaps left open by the vaguer rules on the complaint and redress in art. 17(9) CDSM Directive. As noted, this would have the result of forcing platforms that qualify as OCSSPs and VLOPs to align their copyright redress mechanisms with their remaining illegal

\footnotetext{
${ }^{141}$ Compare also The Santa Clara Principles on Transparency and Accountability on Content Moderation (Santa Clara Principles 2.0), https://santaclaraprinciples.org.

${ }^{142}$ This point is confirmed in YouTube's 2021 copyright transparency report, where it emerges that only $0.05 \%$ of copyright claims via ContentID are contested by users in the first half of 2021 (i.e. 3,698,019 "disputed claims" out of $722,649,569$ total ContentID claims). See Peukert and others (n 11) 10.. See generally on this topic Jennifer M Urban, Joe Karaganis and Brianna Schofield, 'Notice and Takedown in Everyday Practice' (Social Science Research Network 2017) SSRN Scholarly Paper ID $2755628<$ https://papers.ssrn.com/abstract $=2755628>$ accessed 8 October 2021; Niva Elkin-Koren and Maayan Perel (Filmar), 'Algorithmic Governance by Online Intermediaries' in Eric Brousseau, JeanMichel Glachant and Jérôme Sgard (eds), Oxford Handbook of International Economic Governance and Market Regulation (OUP 2018) < https://papers.ssrn.com/abstract=3213355> accessed 20 January 2022.

${ }^{143}$ In this respect, see the proposal for an "institutional intermediary" in this area by Geiger and Jütte (n 51).

${ }^{144}$ See Guidance Art. 17 CDSM Directive (n.25), pp. 20-21, 23-24, and AG Opinion C-401/19, Poland, para 201.

${ }^{145}$ Arguably, they could also reduce costs for platforms, who could scale up their existing mechanisms for other illegal content also to copyright-protected content. But a conclusion on this point would require access to data on the costs of switching systems and the running costs of the current mechanism for running copyright redress mechanisms as compared to future costs under a system with additional procedural safeguards.

${ }^{146}$ Charter of Fundamental Rights of the European Union, OJ C 326, 26.10.2012, p. 391-407.

${ }^{147}$ For a scholarly analysis of the use of the "high level of protection" justificatory argument by the CJEU in this context, see e.g. Marcella Favale, Martin Kretschmer and Paul C Torremans, 'Is There an EU Copyright Jurisprudence? An Empirical Analysis of the Workings of the European Court of Justice' (2016) 79 The Modern Law Review 31.
} 
Quintais And SCHWEMER - ForthComing in European Journal of Risk REgulation 2022

content moderation systems covered by the DSA, thereby raising their level of procedural ex post safeguards in this area.

\section{c) Trusted flaggers/notifiers and measures against misuse}

Another noteworthy novelty relates to the obligation for online platforms to collaborate with certain trusted flaggers/notifiers in art. 19 DSA. Trusted notifiers are "an individual or entity which is considered by a hosting service provider to have particular expertise and responsibilities for the purposes of tackling illegal content online". ${ }^{148}$ Despite the regime in art. 17 CDSM Directive, we expect trusted flaggers to play an important role on OCCSPs also for the flagging of copyright-protected material in the foreseeable future. In fact, in the context of larger OCSSPs, trusted flaggers/notifiers already play a crucial but often opaque role in the privatization of online content (copyright and other) moderation and enforcement. ${ }^{149}$

Recital 46 DSA, for example, notes that for "intellectual property rights, organisations of industry and of right-holders could be awarded trusted flagger status, where they have demonstrated that they meet the applicable conditions". Once again, however, art. 19(1) DSA puts itself in direct connection to the notice-and-action mechanism in art. 14 DSA, meaning that this regime could be related to only those online platforms that are not OCSSPs. Thus, the applicability of art. 19 in the context of OCSSPs depends at least to some extent on the question whether the noticeand-action mechanism applies to OCSSPs, as discussed above. ${ }^{150}$

In the field of copyright and OCSSPs, rights holders may have an interest that online platforms are obliged to collaborate with certain trusted notifiers. Already today, however, trusted flagger arrangements are a common occurrence, at least on larger scale online platforms, like YouTube or Facebook. ${ }^{151}$ The notable twist of the DSA is that the trusted flagger status is awarded by the relevant Digital Services Coordinator of the Member States if certain requirements are met. ${ }^{152}$ Furthermore, the platform is obliged to inform the Coordinator if a trusted flagger submits "a significant number of insufficiently precise or inadequately substantiated notices". ${ }^{153}$ Ultimately, then, the trusted flagger status can be revoked. ${ }^{154}$ In light of uncertainty around the data quality

\footnotetext{
148 Commission Recommendation (EU) 2018/334 of 1 March 2018 on measures to effectively tackle illegal content online, OJ L 63, 6.3.2018, p. 50-61, point 4(g).

${ }^{149}$ See generally Sebastian Felix Schwemer, 'Trusted Notifiers and the Privatization of Online Enforcement' (2019) 35 Computer Law \& Security Review 105339.

${ }^{150}$ See supra at 3.2 .2 a).

151 See, e.g., Google Support, YouTube Help, YouTube Trusted Flagger program, https://support.google.com/youtube/answer/7554338?hl=en, Facebook Response to EU Public Consultation on the Digital Services Act (DSA), https://about.fb.com/de/wp-content/uploads/sites/10/2020/09/FINAL-FB-Response-to-DSA-Consultations.pdf.

${ }^{152}$ Art. 19(2) DSA proposal.

${ }^{153}$ Art. 19(5) DSA proposal.

${ }^{154}$ Art. 19(6) DSA proposal.
} 
of copyright notices, such oversight could be also in particular importance in the context of OCSSPs. ${ }^{155}$

But even if art. 19 DSA indeed were not applicable to OCSSPs, it is important to note that already the non-binding Recommendation (EU) 2018/334 on measures to effectively tackle illegal content online encourages platforms to voluntarily collaborate with trusted flaggers. ${ }^{156}$ Similarly, nothing in the DSA prevents "voluntary" trusted notifier arrangements. These would however be outside the scope of art. 19 and therefore outside the supervision of the Digital Services Coordinator. ${ }^{157}$ This apparent gap is, however, at least partly tackled by art. 20 DSA.

Art. 20 DSA on measures and protection against misuse contains two main angles. First, the obligation to suspend the accounts of users who "frequently provide manifestly illegal content". ${ }^{158}$ Secondly, the obligation to suspend the processing of notices and complaints by individuals or entities or by complainants who "frequently submit notices or complaints that are manifestly unfounded". ${ }^{159}$ In our view, art. 20 proposal is central to mitigating misuse both by users and by any type of flaggers, probably excluding at least partly "trusted flaggers" (regulated by art. 19) but including flaggers covered by "voluntary" trusted notifier arrangements with platforms.

Again, art. 20(2) DSA, however, directly references arts. 14 and 17 DSA. For the application of art. 20 to OCSSPs, thus, once, the central question is whether art. 14 and (at least part of) art. 17 DSA apply the lex specialis of art. 17 CDSM Directive.

The issue of users repeatedly uploading illegal content is as relevant for OCSSPs as for other online platforms. Likewise, the misuse of notices and complaints is a concern on OCSSPs. Art. 17(7) and (9) subpara. 3 CDSM Directive require that the copyright-regime must not lead to the unavailability of non-infringing works, without however explicitly putting in place any protection against misuse. In this absence of specific regulation, we argue that art. 20 DSA should be fully applicable to copyright misuse. This provision is central also for voluntary arrangements (e.g., trusted notifiers falling outside the regime set forth in art. 19 DSA), for which we equally argue it is fully applicable. For reasons of legal certainty, it is desirable that the wording of art. 20 DSA is clarified during the legislative process to state this unequivocally. ${ }^{160}$

\footnotetext{
${ }^{155}$ See e.g. Keller and Leerssen (n 64).

${ }^{156}$ See for an in-depth analysis, Schwemer, 'Trusted Notifiers and the Privatization of Online Enforcement' (n 146).

${ }^{157}$ See, e.g., recital 46, that states: "the rules of this Regulation on trusted flaggers should not be understood to prevent online platforms from giving similar treatment to notices submitted by entities or individuals that have not been awarded trusted flagger status (...)".

${ }^{158}$ Art. 20(1) DSA proposal.

${ }^{159}$ Art. 20(2) DSA proposal.

${ }^{160}$ Outside the scope of this paper, it is also surprising that the misuse mechanism is only foreseen for online platforms, but not other intermediary services (e.g., hosting or even non-hosting intermediary services). Arguably, in light of the DSA's goals, it would be desirable that such misuse mechanism is applicable to all voluntary notice-and-action mechanisms for all intermediary services.
} 


\section{d) Additional obligations on $V L O P S$}

Finally, VLOPs are subject to certain specific due diligence obligations, inter alia, risk assessment (art. 26) and risk mitigation (art. 27). ${ }^{161}$ The functioning and use made of the services of verylarge OCSSPs (e.g., YouTube, Facebook, Instagram) might come with systemic risks, e.g., "dissemination of illegal content" (including copyright infringement) or "negative effects for the exercise" of fundamental rights including freedom of expression. Since the CDSM Directive does in no way address these issues, we do not see any argument that precludes the application of arts. 26 and 27 (as well as other relevant provision such as data access) to VLOPs that are also OCSSPs. ${ }^{162}$ The same reasoning holds for other relevant obligations, such as data access and transparency. ${ }^{163}$

\section{Conclusions}

In this article we have looked at the (potential) relationship between the horizontal DSA rules and the sector-specific rules for OCSSPs in art. 17 CDSM Directive from a legal doctrinal perspective. Rules on copyright-vis-à-vis other forms of information (or content)-appear to have a special place in the EU legal order. Meanwhile, the European Commission has provided (internally) some insights on their interpretation in a presentation to Council Working Party on Intellectual Property (Copyright). ${ }^{164}$ In that presentation, the Commission reminds that the "DSA is not an IPR enforcement tool" given its general and horizontal nature but that it "includes a full toolbox which can be very useful for the enforcement of IPR", which would apply "without prejudice to existing IPR rules". Notably, however, the Commission considers that art. 17 CDSM Directive remains "unaffected; i.e., DSA rules on limited liability, notice and action, redress and out of court mechanism [are] not applicable for [OCSSPs]". Our analysis of the DSA proposal leads to a different conclusion, painting a more complex picture.

In our view, the reference in the DSA to "unaffected" does not mean its horizontal rules would not supplement those in art. 17 CDSM Directive, especially as it regards notice-and-action or redress

\footnotetext{
${ }^{161}$ For an analysis of these provisions, see e.g. Buri and van Hoboken (n 13); Joan Barata, 'The Digital Services Act and Its Impact on the Right to Freedom of Expression: Special Focus on Risk Mitigation Obligations' (PDLI 2021) <https://libertadinformacion.cc/wp-content/uploads/2021/06/DSA-AND-ITS-IMPACT-ON-FREEDOM-OF-EXPRESSION-JOAN-BARATA-PDLI.pdf $>$.

162 See, similarly, as regards risk mitigation Peukert and others (n 11) 10-11.

${ }^{163}$ See, similarly, as regards transparency provisions Peukert and others (n 11) 5-6, 11-12. On the topic of transparency in the DSA proposal, see e.g. Paddy Leerssen, 'Platform research access in Article 31 of the Digital Services Act' (Verfassungsblog, 7 September 2021) <https://verfassungsblog.de/power-dsa-dma-14/> accessed 8 October 2021.

${ }^{164}$ Council of the European Union, Working Paper, N ${ }^{\circ}$ Cion doc.: 14124/20, Digital Services Act and EU copyright legislation - Information from the Commission, Brussels, 01 March 2021 WK 2824/2021 INIT (on file with the authors).
} 
Quintais AND SCHWEMER - FORTHCOMING IN EuROPEAN JOURNAL OF Risk Regulation 2022

mechanisms. ${ }^{165}$ Rather, on the basis of the available proposal and amendments thus far, we argue that the DSA will probably apply to OCSSPs insofar as it contains: (i) rules that regulate matters not covered by art. 17 CDSM Directive; and (ii) specific rules on matters where art. 17 leaves margin of discretion to Member States.

Category (i) applies to some provisions in the liability framework rules ${ }^{166}$ of the DSA and most clearly to procedural obligations. This makes sense since, in our view, the special role of copyright, as noted above, may only be related to substantive copyright law. But the DSA's due diligence obligations we have examined relate to information requirements, quality assurances regarding notices, and procedural safeguards for the ex post control with a view to, for instance, reinstate non-infringing content. In this light, we find no strong argument for why EU copyright law would require a full exemption from procedural obligations set out for online platforms in the DSA. In fact, the very character of the proposed DSA (and e-Commerce Directive that precedes it) is to provide broad and horizontal rules for a level playing field. Where no more specific regulation of art. 17 CDSM Directive applies, the asymmetric due diligence obligations of the DSA should apply.

The situation is trickier for category (ii), which relates to areas where art. 17 CDSM Directive does in fact provide for some degree of regulation, and it is uncertain to what extent it preempts more detailed rules in the DSA. The situation is further complicated by the Commission's Guidance on art. 17, despite its non-binding character. In our view in any case, the logical approach appears to be to consider the CDSM Directive's regulation as lex specialis. Where this lex specialis, however, does not contain specific or more detailed regulation (or an explicit exemption from the general rules), the horizontal rules of the DSA would apply once it comes into force. ${ }^{167}$ This is despite the different nature of the legal instruments at issue (Directive vs Regulation), the territorial nature of copyright, and the potential issues arising therefrom from the perspective of multilayered enforcement. These problems may be attenuated by the harmonizing effect of the Commission Guidance on art. 17 on Member States' laws and OCSSPs practices.

From a normative standpoint, we understand the DSA's due diligence obligations as "first principles" of how internet intermediaries, and most notably platforms and VLOPs, must "behave", and how competing fundamental rights of involved parties can be balanced. In other words, the DSA's due diligence obligations should be viewed as the horizontal fallback regime that would only be altered by more specific lex specialis rules. That is to say, as a horizontal framework, the DSA sets out the default legal regulation for the intertwined relations of platforms, users and

\footnotetext{
165 The Commission's presentation itself continues to lay out possible "complimentarity" of the DSA rules with regard to art. 17 CDSM Directive, namely for "e.g. transparency obligations with regard to action taken by the online platform; trusted flaggers". See id.

166 See supra at 3.2 .1 .

167 This understanding is also supported by recital 11 DSA proposal, which clearly only relates to "specific rules and procedures" (our emphasis). Naturally, before the DSA is approved and comes into force, national laws can make use of the margin of discretion available to them in this respect under art. 17 CDSM Directive.
} 


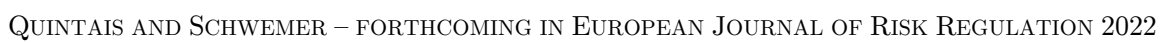

rightsholders. ${ }^{168}$ As such, even in the presence of specific non-exhaustive sector regulation, the DSA rules should remain applicable unless they are clearly set aside by the lex specialis.

In this light, our analysis identifies several rules in the DSA proposal that should apply to OCSSPs despite the regime in art. 17 and the accompanying Guidance: on notice and action, internal complaint and out of court dispute settlement, trusted flaggers/notifiers, and measures against misuse. ${ }^{169}$ But we have also identified a number of gray areas in these overlaps between the DSA and art. 17 CDSM Directive. To avoid legal uncertainty, it would be important to clarify these during the legislative process, thereby mitigating the risks associated with multi-layered enforcement on OCSSPs. This could be achieved, for instance, by stating that Chapter III DSA (arts. 10 to 37) applies as horizontal framework mutatis mutandis also to those intermediary services covered by other secondary legislation, to the extent no more specific rules are laid out. Further precise clarifications could be introduced in the specific gray areas identified in our analysis, in order to ensure the applicability of the DSA's safeguards to OCSSPs, where justified. After all, although we can all agree that copyright is special, it should not be a barrier to setting "uniform rules for a safe, predictable and trusted online environment, where fundamental rights enshrined in the Charter are effectively protected". ${ }^{170}$ In this respect, although our analysis focuses on the intersection of the DSA with copyright law, as we have noted throughout, our analytical framework could prove useful to further research and clarify the overlap of other sector-specific rules on different types of online platforms - such as in the Terrorist Content Regulation and the AVMSD - with the DSA. It could also serve as a reminder and blueprint for future national and EU legislative endeavors in the area of platform regulation to carefully consider their interplay with the DSA.

\footnotetext{
${ }^{168}$ Which, in our example, relates to copyright right holders, but could also be the holder of another protected right. 169 See supra at 3.2.2.

${ }^{170}$ Art. 1(2)(b) DSA Proposal (setting out the aims of the Regulation).
} 